\title{
APURDUTI
}

Euskal ikerketen aldizkaria | Revue d'études basques |

Revista de estudios vascos | Basque studies review

$11 \mid 2006$

Numéro XI

\section{Esamoldeak Jean-Baptiste Etxeberriren (1903-1996) obran}

Jean-Claude Iribarren

\section{(2) OpenEdition \\ Journals}

Édition électronique

URL : http://journals.openedition.org/lapurdum/301

DOI : 10.4000/lapurdum.301

ISSN : 1965-0655

\section{Éditeur}

IKER

Édition imprimée

Date de publication : 1 novembre 2006

Pagination : 171-202

ISBN : 978-2-86781-474-7

ISSN : $1273-3830$

Référence électronique

Jean-Claude Iribarren, «Esamoldeak Jean-Baptiste Etxeberriren (1903-1996) obran », Lapurdum [Linean], 11 | 2006, Sarean emana---an 01 mai 2008, kontsultatu 06 mai 2019. URL : http:// journals.openedition.org/lapurdum/301 ; DOI : 10.4000/lapurdum.301 


\section{Esamoldeak Jean-Baptiste Etxeberriren (1903-1996) obran}

Jean-Claude IRIBARREN

Jean-Baptiste Etxeberri apezaren lau liburuetako esamoldeak bildu ditut artikulu honen osatzeko. Lau liburuak dira: Frantziako erregina, Baiona, 1996 ; Hazparneko misionestak, Baiona 1986 ; Denetarik, Baiona, 1998 ;. Lehengo eta oraiko gorabeherak, Baiona, 1991 denak Cordeliers inprimategian eginak. Jean-Baptiste Etxeberri Donoztirin sortu zen 1903-an eta abantzu joan den mende osoa iragan 1996-an zendu baitzen. Bere kondu publikatu zituen 13 liburu. Zergatik hautatu ote dut JB Etxeberriren liburuak lokuzio batzuek ikertzeko? Koldo Mixelenak berak baitzioen harekin behar zela euskara ikasi.

Bildu ditut beraz 159 esamolde, balio desberdinetakoak eta hain segur ez dira oro egiazko lokuzio, baina halere nere ikuspegitik ohargarriak direnak eman ditut. Adibidez, aho aberatsekoa izan lokuzioa da, hitzen konbinaketa arras finkatua baita, baina tomate iduri biperra edo tapikatu zolagunea formak literarioak izan daitezke. Foltsua ikertu formaren adiera aldatzen da ere erran nahi figuratiboan erabilia den ala ez kontuan harturik.

Baina gisa guziz esamolde horiek ez dira egilearen iduripenaren eta asmakizunetaren arabera bakarrik jiten. Islatzen dituzte haren eguneroko mintzairaren aberastasuna. Esamolde horiek konparatu ditut Lhandek eta Orotariko Euskal Hiztegia-k ekartzen dituzten adibideekin, sarean Koldo Izagirreren ondotik egina izan den lokuzioen biltze handiarekin, eta Euskaltzaindiko korpusarekin. Ondotik bildutako esapideen baliokide frantsesak bilatu ditut, bereziki Rey-en Dictionnaire des expressions et des locutions hiztegia baliatuz.

Esamoldeak zerrendatu ditut alfabetikoki eta bi indize egin, bi sartze mota aurkeztuz: lehenik bildu nituen euskarazko esaldiak eta haien baliokide frantsesak, eta bigarrenik bildutako baliokide frantsesak eta haien kide euskarazkoak. 
Ohartu naiz JB Etxeberriren euskara aberatsa dela: nahiz haren lokuzio guztiak ez ditudan bildu, Euskal lokuzioen korpusean kopuru handian daude, ez errateko korpusaren parte handiena egiten dutela. Bestalde baliokide frantsesak esamoldeak badituzte bainan ez beti, eta itzulpena ezinezkoa delarik guztiz opako edo ilun gelditzen dira. Adibidez horra nola etortzen diren:

Zure aboa bete izan (4. zenbakiduna ene bilketan) ???

Ohoreak-oharatei (107) 'quoiqu'il en soit des honneurs, faisons fi des honneurs'?

Pasa errexa izan (115) 'se contenter de peu'.

Xitxi-paperetan (ibili, artatu) (147) 'gâter qqn' ???

Zerika izan (151) 'au sujet de quoi'.

Zehe bat sururrekin gelditu 'rester comme deux ronds de flan'.

Erran molde mota honen ulertzeko euskararen adimena eta intuizioa baitezpadakoak dira. Frantsesez gauza bera gertatzen da 'à bout de souffle', 'mettre de l'eau dans son vin, assurer sa matérielle, avoir le bras long, avoir les yeux plus gros que le ventre, donner des bâtons pour se faire battre' gardenak dira eta haien ulertzeko frantsesaren ezagutza handia ez da beharrezkoa. Aldiz 'travailler pour le roi de Prusse (travailler pour rien)', 'les boufs-carottes (la police des polices)', 'être fleur-bleue (être sentimental)', 'faire un pataquès (faire une bourde)', 'mener une vie de bâton de chaise (avoir une vie désordonnée)' opakoak dira. Alta erabiliak dira arazorik gabe nahiz eta zuzen jakin gabe nondik jiten diren. Ulertuak dira edo erabilaren indarrez ('avoir le bras long, être dans le coaltar') edo elgarrekiko erreferentziak baititugu ('aller de Charybde en Scylla, arrête ton char Ben Hur'). Erreferentzi amankomunak ditugularik esamoldeak desbideratuak izaten ahal dira, beste konotazio batekin: 'de Charybde en Scylla, de caraïbe en syllabe'2. Bainan ohartu behar da frantsesez ere badaudela esamolde arrunt konprenigabeak, beharba guti erabiliak baitira. Adibidez, 'plier les gaules' (finir un travail) ${ }^{3}$, 'avoir les côtes en long' (être paresseux, original, bizarre) ${ }^{4}$.

Euskaraz ere gauza bera gertatzen da: erran moldeak ardura erabiliak baldin badira, gardenak dira gehienetan: aberats okitua izan, aboan bilorik gabe erran, hogeita hameka eta esku izan, mutur salda merke ukan. Beste batzuetan ilunagoak dira ez baitira usu erabiliak, ahoan kurutze egin ('gose izan'), apoaren salan ezarri ('mettre en boîte'), arautsu bat mintzatu ('parler grosso modo'), norbaiti kausitu ('trouver grâce aux yeux de qq'un'). Azken muturrean, esamolde batzuk erabiliak dira adiera malguarekin ${ }^{5}$, hala nola, zure aboa bete izan (4), xitxi paperetan artatu (147) aldietan bezala. Euskaraz ere hitz jokoak egin daitezke, nor gira gu-tik nor gira gueneko izan-era iganez adibidez. Ohartu behar da ere lokuzioak orain sortzen direla, hala nola erostoria joan ('aller à l'hypermarché'), gaubasa egin ('faire une fête ayant duré toute la nuit avec une intensité peu commune'), nekaporraturik egon ('être crevé') ${ }^{6}$.

1 - Coaltar, goudron, 'être dans le coaltar, dans le cirage, les vapes', à demi inconscient (A.Rey, 207)

2 - Splendeurs et misères des courtisanes, Balzac, p 842.

3 - 'Plier les gaules', arrantzazale bat bezala 'bere kirola' amaitu duenean, bainan har dezake ere adiera argotikoa eta erotikoa.

4 - 'Avoir les côtes en long','aueras costas al loune' vieux mots utilisés en Barousse, (ne vouloir ni se courber ni se ployer dans son travail) Célineren Mort à crédit-ik hartutako adibide batekin, in Rey, 246.

5 - Bakoitzak interpretatzen duelarik bere inguruan erabilia den gisara.

6 - Mantxut lokuzioak, Urmeneta A, komunikazio biziagoa, Lasarte, 2000-2002. 
Beraz eta bururatzeko, esamoldeak zer? Mintzaira baten altxorra (joiak ${ }^{7}$ ) eta halaber haren biziaren ${ }^{8}$ lekukoak, hizkuntzaren "foltsua"? Uste dut baietz.

Hemen aurkeztuko ditut nere zerrendako lokuzio batzuk:

1. Aberats okitua izan: Adibidea: [Charles de Foucauld] aberats okitua zen. Zorigaitzez sei urte zituelarik galdu zituen ontasun bebarrenak: bere aitamak (13, 85, 2). Azalpena: 'arras aberatsa'. Okitu, okbitu, millionnaire, richissime, bainan ere jakitun okitua: grand savant, zahar okitua: vieillard décrépit, (Lhande). Orotariko Euskal Hiztegia (OEH laburduraz hemendik aintzina): Okitua: aberats okitua: millonnario, erraiten zuten aberats okitua, urrez hantua zela, (Zubiri, 1958, 85). Zahar okitua: decrépito. Jakitun okitua: sabio repleto. Sarean ez dago.

F: 'riche comme Crésus' (ce roi de Lydie était riche... et montrait une certaine naiveté dans l'étalage de ses richesses) Rey.

3. Aho aberatsekoa izan: bera ere abo aberatsekoa zen, bat izaitekotz (9, 39, 20). Azalpena: 'mintzalari ona izan', 'ele onekoa izan', 'baikorra izan (Dominique Duhalde Lekuineko lekukoaren arabera). Lhandek ez du ekartzen. Ez dut OEHn atzeman, aho handi, abobero izan lokuzioak hurbilenak direlarik: 'exagerado'. Abo bero, espantotx: Ameriketan zonbeitek diote Krutchev abo-bero bat dela, dena espantu, (Herria, 2-1-1958). Euskarazko kidea: mibia pikoan ukan (Bidegain, 145). Sarean ez dago.

F: 'parler d'or', (St Jean Chrysostome "bouche d'or"), Rey. 'Positiver'.

7. Ahoan kurutze eta mahain petik hixtu egin: Beibalako putiko tipi batek goiz guziez mende bunen hastapenean arto eta esnea zuen eta zokolet-esnea urteak betetzeko egunean. Anartean aboan kurutze eta mabain petik hixtu! (13, 87, 21). Azalpena: Charles de Foucaulden tripa handiaren denboran, beste haurrek maizenik guti jaten zuten. Ahoaren aintzinean kurutzea egin, eta gero barur egin. 'Jateko deusik ukatea' erran nahi baitu. "Ahoan kurutze" 'ixilik egon' erran nahi du ere (D. Duhalde). OEH: aboan gurutze utzi naute, BN, 'me han dejado con un palmo de narices', ils m'ont fait un pied de nez' [???] Sarean ez dago.

F: 'crever la dalle' ; 'tirer la langue"' ‘être dans le besoin', Rey.

4. Ahoa (zure ahoa, haren ahoa) bete izan: Duela bamabost urte ospitalerat etorri zaukun adinetako emazte bat. Laster obartu nintzen eni so eta irriz hasten zela. Halako bat egiten dautzu trufa-musika borrek, bizkar bezurrari bebeiti beldu zaitzularik. Hurbildu nindakon, ez hoberena gogoan, egiten nuela ene baitan: zerika dut emazte gaizki ikasi hau? ... Zerendako irri egiten dautazu? Ez niza ote zure aboaren bete?" $(9,57,7)$. Adiera: 'errespetua merezi ukatea'. 'Harremenetan, besteak bezalakoa izan'. Hemen, mintzo denak gogoan duena hauxe da: 'zergatik nitaz trufatzen zara, ez duta zure errespetua merezi'? Lhande: Aho bethez: 'à pleines bouchées': ez da gauza bera. OEH: Abo beteka 'a boca llena', abiertamente.'.

7 - Familiako joiak, frantsesez duen adiera argotikorik gabe.

8 - Adibideak zerrendaturik dira liburuak agertu dataren arabera, erran nahi baita : Frantziako Erregina (3), Hazparneko misionestak (9), Denetarik (11), Lehengo eta oraiko gora-beherak (13). Ondotik agertzen dira lokuzio aipatuen orriak eta lerroak. 
Erhotegi batean mediku bat ari da abo betheka erho guziak sendatzen dituela, (Egunaria, 24-11-1960). Ahoa bete: 'Ozenki', ahoa betez bazerasazuten: ez zutela xede gaixtorik erlisioneari buruz" (Hiriart Urruty, Zezenak errepublikan). Lokuzioak sarean, Intza proiektua: Ahoa beteko izan: 'ospetsu'. "Amerika, Afrika, Madrid, Barzelona, aua beteko izen oiek zer ote zeukaten ikasi nairik. Ataño, Txantxangorri kantaria, 1979. Aboa bete hortz, 'txunditurik': Larranekoak aoa bete ortzekin gelditu ziran", Agirre, Garoa, (Esamoldeak Erabili Com).

Bainan Etxeberriren adiera honekin berarekin ez dut korpusean beste adibiderik ikusi.

F: 'mériter le respect de qqn (le vôtre, le sien)'. Ez da, ene ustez, frantsesezko baliokiderik.

6. Aho xuri izan: [Charles de Foucauld]) bartze onekoa zen segur bainan zotza bezein alferrra. Bertzalde abo-xuri, ahalge gabe gormant erakutsia" $(13,85,18)$. Azalpena: 'gormanta', 'mutur-xuri' (P. Xarriton, Hiztegia euskara-frantsesa, Donostia, Elkar, 1997: hemendik aitzina X laburduraz markatua). 'Mutur-xuri' eta 'aho xuri' artean desberdintasuna badaiteke. "Aho xuri egin" gehiago izanez, besteez trufatu. Aho xuri, 1) délicat pour le manger, gourmet. 2) fig. bégueule. (Lhande). OEH, II, 213: friand, délicat, gourmet. Landerretxe, RIEV 1908, 624, euskalhizkuntza edo kantabrismo (giros o expresiones propias del euskara: cf. castelinismo, galicismo). Euskarari euskal itxura begira dezoketen mintzatzeko molde bakharrak. Hala nola: gogoak emanik, berean bere, aho xuri, etb.

F: 'avoir le bec fin, mais aussi bégueule'.

8. Ahuntz esnean galkatu: egun batez ... hurbildu zitzaion gizon bat arras bere gisakoa. Begiak ñir-ñir, gaxuratik sobera bortxatu? Abuntz esnean galkatu? (13, 80,14). Azalpena: 'esnea ausarki edan', 'esnean ito', '(se) gaver' (Lhande). OEH : Ahuntz-esnea, 'leche de cabra, que se prescribía à ciertos enfermos'. Auntz esnia artzen zan, esate baterako, errapetik aora, autzduna etortzen zalako atera ; 'la leche de la cabra se tomaba, para un decir, de las ubres a la boca, porque la cabrera solía acudir a la puerta' (Etxeberria, Euskera dialectal de Eibar). Sareak ematen du Etxeberri-ren beste adibide bat eta dio: 'ahuntz esnean galgatua izatea, menditarra, landu gabea izatea da', ahuntzen haztea laborari xumeen zortea zelakoan.

F: "abuser de l'eau fraîche, de l'eau claire" est peut-être une expression française locale.

9. Ahuntzaren gauerdiko eztula bezala izan: gizon maltzurraren bitza ala abuntzaren gauerdiko eztula biak berdintsu (3, 65, 11-12).Azalpena: 'baliorik gabekoa izan'. OEH : Abuntzaren gauerdiko eztula' : 'expresión que tiene el sentido de cosa insignificante, sin importancia' ; eta zer axola du bonek hemen darabilgun hauzian? Abuntzaren gauerdiko eztulak baino gehiago (Mitxelenaren idazlan bautatuak, 1972, 82). Beste adibideak badaude sarean: Ia ba, milloi bat baiedauka zimarroi orrek eta ...? Milloi bat! Auntzaren gaberdiko eztula da!? Ta milloiagatik zimarroia edo izurde ustela artu bear da senartzat? (Agirre, Kresala) in Erabili.com/esamoldeak. Mille ogerleko diñosu? Ene semea, ezta auntzaren 
gaberdiko eztula (Zamarripa, Manual del vascofilo). Nik uste, eskari oien etorkizuna ta auntzaren gauerdiko eztula or nonbait ote diran (X. Lizardi, Kasetari lanak). Erabili.com/esamoldeak.

F: 'nul', sans valeur, avec un sens plus éloigné, nul et non-avenu? (inexistant, qui ne compte pas, expression d'origine juridique, au sens de sans valeur légale).

10. Akamarreko, Akamerreko bidezainak (norberaren) buruari irri egin: Adibidea: [gerla denboran autoreak arnoa gudu tokira eraman zuen eta lagun batek han ebatsi zion] lebenbiziko gauean ebatsi zautan eta bustu, egun bartan ere irri egin zautan Akamarreko bidezainak (13, 110, 9). Erranahia: Akamarre (Cames), Lapurdiko herri kaskoina eta Akamarreko kantonierra (herri tipienetarikako langile xumeenetarik) nitaz trufatu zen. Arras trufagarri izan nintzen.

F: 'être le sujet de la plaisanterie'.

11. Akilimarro ikusi: [Charles de Foucauld 1881ko Algeriako gerlan], laster pairatu zituen- eta nolako kuraie kalipuarekin -zinak eta minak. Ikusi oraino ez izarrak eguerditan bainan, euskaldun zirtolariek dioten bezala, ikusi akilimarro, galtxagorriren zazpi adar makatzaile uspelkorrak (13, 89, 28). Azalpena: 'Sufritu','pairatu'.

'Akhilimarro', surnom désignant le diable (Lhande). OEHn ez dut atzeman. Sareak ematen du adibide bera.

F: 'souffrir comme un damné' (Rey), souffrir mille morts (ibid.), 'souffrir comme un possédé' (ibid.755).

16. Apoaren salan ezarri: [Manex Athor Heletako apez xumeak egin predikuaz] Eta nik aldiz ene baitan: "aldez edo moldez, huts ala kausi, hitz guziak gain azpikatuz ezarriko zaituztet apoaren salan! Berma hor, Attor! (13, 110, 26). Adiera: 'nausitu', 'garaitu', 'mettre qqn en boîte', 'faire marcher', 'monter à l'arbre', 'emmener en bateau' (Rey, 90). OEHn ez dut atzeman. Apo: 1. 'crapaud', 2. 'apocado, falto de carácter'. 3. 'verraco, cerdo semental', 'putanero'. Sarean ez dago.

F: 'bon tour', 'mauvais (sale, vilain) tour' (notamment avec le verbe jouer) (Rey) 'Mettre en boîte'.

17. Arautsu bat mintzatu: Bizkitartean, ez uste izan arautsu bat mintzo nizala (9, 30,1). Azalpena: 'arautsu', 'approximatif': Etzirogu ikbus Iainkoa arautsuz bezik (Rodriguez 1782 in Lhande). OEH : arau, 'règle', 'selon': arabera. Arautsu: 'ajustado a la razon' (?), gutiz gehienak harritzen dira berri hori jakitearekin. Alainan denak arautsu batez arizanak erraiten nor izanen zen izendatua. Arautsuz: 'à peu près', ik. Lhanderen zitazioa.

Ikus hurbil diren hitzak: arauz, araiz, nonbait han, 'probablement', 'sans doute', 'peut-être' (OHE). Sarean ez dut atzeman.

F: 'en gros, grosso modo', 'sans entrer dans le détail' (Rey). 
18. Ariaren bortxaz: bizkitartean ariaren bortchaz pindar zonbeit jauzi ziren harri-peña bezein gogorra zen buru bartarik (3, 96, 25). Azalpena: 'à force de travail". Ari, hari: 1) vaquer à, s'occuper à, "iruten ari nuzu". 2) travailler. Ariz-ariz, en faisant. 3) ari: adjetiboa, 'zer gizon aria', 'quel homme travailleur' (Lhande). Ari, arian, 'trabajando, ocupándose' (OEH). Arian-arian, 'a fuerza de ocuparse' (ibid.) : Sagasti berri, sagasti zuri/ inguma- atsegintokia iduri/ elurte arian geldia (Lizardi, Bibotz Begietan 1932, 112 or.). Sarean: nolabait ere sartu bear zian arian/ bapo jan eta edan lertzeko zorian/ ez giñan bildu noski eliz-atarian/mutillak, etzan giro apal ondorioan! (Goierriko loreak, 1970)..

F: 'A la la force du poignet', ' par de grands efforts personnels' (Rey).

20. Aseta pasaia (izan): Han zabilan beraz De Foucauld jo harat jo bunat-aseta pasaia- mundu buntako itzulia egina balu bezala azken fluxtasun ez deus hautan $(13,93,4)$.Azalpena: 'aseta', 'asearen' bariantea. 'Pasaiaz', 'bidaiaz asea' 'Fatigué du voyage'. Asetasun: Satiété (Lhande). Asetasun: 'saciedad', 'satisfaccíon', 'hartura' (OEH). Nere gosea bilen baituzu asetasun miragarriz, eta gorputz ustel au betiko ustelgabez iantziko (Orixe1956, 280). Sarean ez dago.

F: (en avoir) "jusqu'à plus soif"(Rey), "en avoir marre de" (ibid).

22. Azen ontzeko: Orduko gobernariek manuz behar zuten Maroc eskualdea nolakoa zen erran errotik azpiz goiti eta gain behera. Bainan nun atzeman bilari aski entzunak eta atrebituak. Gebiago dena, azen ontzeko, nagusi marokanoek aboan bilorik gabe errana zuten bilen zituztela piru hortako salatari, espiunak (13, 91, 20). [L. Ed. Cestac] Bertzeak beste -azen ontzeko- behar zuen oraino etxe-gizon eta ekonomoa bezala egun guzietako aphairuez eta gaineratiko guziez artha bartu (3, 120, 36). Azalpena: adiera figuratiboan, 'gauzak hobetzeko' bainan hemen zentzu ezezkorrean. Ardurenean, 'gaixtotik gaixtorenera'. Adiera hurbilean, ikus sasitik berrorat. 0EH: azak ontzea ez dut atzeman. Aldiz, azen azpitik zopa jan, "manger la soupe par dessous le chou qui la couvre, cela se dit quand un domestique ou qqn d'autre auquel on se fie fait une suupercherie". Dena jukutria tzar, azen azpitik zopa jale, harrria bota eta eskua gorde (Etxeberry JB, 1962, 26).. Azen ontzeko, segurra ere ixlamista deitu boriek biltze bortaz baliatuko direla oraino herria gehiagoren sustatzeko... azen ontzeko, langile zindikatak haserre, jende xeheak duela aintzina pekatuko! Soxialistak ere kexu, ez dela hori bide ona (Herria, 1995), in lokuzioak sarean.

F: 'qui mieux est', 'en outre', 'encore mieux', 'encore pire', 'pour tout arranger' (Rey).

23. Azken beltzean: [zahartzerakoan] orok dakiguna, eta zonbeitek gure gostuz ikasia, zahartzerakoan itaxurak zorta larrietan abiatzen direla. Bainan desmasiak bor baitira azken beltzean (13, 67, 13). Zorigaitzez azken beltzean-eta nolako bibotzminarekin- amor eman beharko du [L.Ed. Cestac-ek] eta bortan utziko ditu bere Pariseko ichtudio, ikaskuntza handiak (3, 120, 22). Azalpena: 'parada gaixtoenean'. 'Au pis aller '(Lhande, 138). OEH : 'en rigor', 'en último término', por pura necesidad'. Ta gero, nork zuekin eskondu nai? inork ez alabok: azken beltzean 
umezurtz ta neska-zar bizi-bearrez zaudetek (Itun berria, 98). Lokuzioak sarean : Gogoan eman zezatela errient horiek, beren onetan; bere zedarrietan ez bazauzken, etzakitela, zeri zauden; aiber zela gobernamendua gerla bilatzen gaztigatzeko, boben arau, toki alda, paga ken edo ttipi; azken beltzean errebolta (?) (Hiriart Urruty, Zezenak errepublikan).

Fr: 'au pire', 'au pis', 'au pis-aller', 'en supposant l'éventualité la plus fâcheuse', (Rey, p 725). 'En dernière extrémité'.

24. Azkenaz goiti: [Lacordairek] aditu zuen Sainduaren (Arseko apezaren) predeikua eliza tiki hartan. Mintzaldi zitakeen xinpleena bainan, azkenaz goiti, bihotzetik ateraiak ziren suzko ateraldiez ausarkian orbatuak (13, 82, 20). Azalpena: 'funtsean', 'mais pour finir' . Lhande : 'Après tout, finalement '. OEH: Eztuzu nahi emazte gaixtoa, ez seme gaixtoa, ez zerbitzari gaixtoa, ez athorra gaixtoa, ez eta azkenez goiti zapata gaixtoa ere (Axular, Guero, 564). Sarean, adibide bakarra Etxeberriren adibide bera da.

F: 'à la fin'. ('à la fin des fins', 'à la fin finale' sont des formes superlatives) (Rey, p 419). 'En dernier ressort'.

25. Aztura tartarika ukan: barka otoi ene bazter solasak. Ezpaitut oraikoa aztura tartarika hori." $(13,80,7)$. Autoreak dio bera aspalditik kalakaria dela. Azalpena: 'tartar', hitz onomatopeikoa, 'kalaka' (beste hitz onomatopeikoa). 'Bavardage, personne bavarde et qui rapporte tout ce qu'elle voit et entend (Lhande). Aztura: 'jite', 'izate', 'nortasun'. OEH : Aztura 1) 'coutume, habitude, mœurs, vieilles habitudes'. 2) 'expérience'. 3) 'mode, manière'. Biluzi naiz behin aztura gaixto guzietarik, nola bada berriz beztituko naiz (Axular, Guero, 472)? OEH : tartarika, : 'boniment, charlanaterie'. Apezekilako betiko tehenta, (leloa, errepika, tartarika)... Dantza ez haizu (Laffitte, Murtuts eta beste, 108). Sarean ez dago.

F: 'être bavard comme une pie' (Rey, 710).

28. Barneak farrasta egin: barneak farrasta gozoena egiten dautzu aspaldiko adixkide xaharren ikusteak $(13,110,1)$. Azalpena : 'bihotzeko mugimendu sakona'. 'Emotion ressentie, barneak farrasta egin zautan (Lhande). Farrasta: 1. ) le bruit d'objets que l'on traîne, remue, frotte, de liquides que l'on répand, qui se précipitent et coulent avec force, que l'on agite vivement, 2) farrasta, parrasta: une certaine quantité de. OEH : Athea idekitzean farrasta bat egiten dio bihotzak, desegiten zaio begithartea (Laphitz, 1867, 114). Etxepare medikua: Aire boxpil batek phagoen abarrak, farrastatuz, elgarri xaflatzen ditu xurruntxa ezti batekin (Beribilez).

F: 'faire battre le cœur' (Rey, 214), (faire en sorte que) 'le cœur batte la breloque', "Monsieur de Nissen, dont le cour battait la breloque, crut un instant que sa femme voulait le provoquer" (Blondin, Les quat'saisons, 98 (ibid., 119).

30. Beharriez burukitari (lo egin, lo egin gabe): Hobenduna aldiz, bi beharriez burukitari, lo zurrungan! Gauazko ttirita guziak kurrukaz ari diren denbora 
dohatsuan..." (9, 64, 5). Azkenean, ezagutu ondoan gure bizio txarrena behar diogu gerla egin, bi beharriez burukitari egon gabe" (3, 19, 25). Izanen du nun zeri loth bi beharriek burukitari egon gabe (3, 120, 31). Adiera: 'benetan, arras ongi lo egin'. Edo alderantziz, loak hartu gabe zerbait egin'. Lhande (189), burukita, 'oreiller'. Buruki, burukita, 'oreiller' (OEH, V, 729): Burukitik burukira (Baztan), 'de cabo a rabo', 'de bout en bout', 'de la tête aux pieds'. Sareak ematen du JB Etxeberriren $(9,64,5)$ adibide bera.

F: 'dormir sur ses deux oreilles' s'oppose à 'ne dormir que d'un oil'. Locutions voisines: 'dormir comme un ange, un bienheureux, un loir, une marmotte, un plomb, un sabot, une souche, une toupie' (Rey, 327). 'Dormir du sommeil du juste': d'un sommeil que rien ne trouble (Rey, 526).

31. Behautzu hortik, Kitolis: [apez landibartarra] Horren gatik ez uste izan haren solasak etzutela buru buztanik ardurenean: behautzu bortik, Kitolis, hor konpon, Mari Anton! (13, 108, 6). Emazu bortik eta ni ez ezar gaitzi gogorrean $(13,71,18)$. Erranahia: 'Emazu hortik', hor konpon'. 'Allons donc, vous plaisantez ' (Lhande). $\mathrm{OEH}$ : Beha 'écouter, prêter attention', beha lehenik, mintza azkenik (Oihenarte, Atsotitzak, 79). Behozu othoi Jainkoarean oneziari eta ez haren azoteari (Itun berria, 1983, 36). Sarean ez dago. Hemen 'allons donc, et ne me vexez pas, ne m'offensez pas gravement'.

F: 'et allons donc', impératif ironique qui souligne une action malheureuse, qu'on désapprouve (A.Rey, 17).

34. Berenak eta asto beltxarenak erran: bertzalde hango guardiano salbaieri erran zituen berenak eta asto beltcharenak beren baitan sar arazteko $(3,58,22)$. Azalpena: 'erasiatu'. Lhande : berenak eta asto beltxarenak entzun, entendre de belles remontrances. OEHn ez dut atzeman. Sareak ez du ematen.

F: 'dire à quelqu'un ses quatre vérités'. 'Dire ce qu'on pense de lui avec une franchise brutale'. (Rey, 907), 'dire, entendre des vertes et des pas mûres', fait référence soit à des histoires lestes soit à des histoires désagréables (Rey, 909).

35. Bihotz higuintza batekin (aitortu): Bide nabar, zendako ez dut aitortuko, bihotz biguintza batekin, egona nizala haren otoitz-lekuan komentu hartan Ardèche departamenduan $(13,96,3)$. Erranahia: adibidean, bihotz herstura batekin' 'avec un serrement de cœur'. Normalean, 'higuindu': 'aiher izan', 'gorrotatu', 'hastiatu'. Lhande : Higuintza, 'répugnance, détestation'. OEH : Higuintza: 'dégoût, horreur, répugnance'. Sarean ez dut atzeman.

F: entre 'avoir le cour serré, avoir le cœur gros', (même effet de sens) (Rey, 213) et 'avoir le cœur au bord des lèvres', envie de vomir (ibid., 209).

36. Bihotzeko pinpili-panpalañoa ukan: Berekin eraman zuen gure biligarroak, eskolako itzul-inguruetan ezagutua zuen bertze motako lertsun bat. Hori baitzuen bibotzeko pinpili panpalañoa (13, 87, 33). Adiera: 'Maitalea', 'maitatuena'. 
Lhande : Avoir une préférée (dans son cœur). Préférée de mon cour. OEH : Pinpilipanpala, pinpili-panpa: predilecto. Sarean ez dago.

F. 'Porter quelqu'un dans son cour'. Remarquer qu'en français, cette locution ne s'emploie que négativement (Rey, 214)

41. Dupin guzietako zalhia: bainan hor baita trebes Louis VI errege saltseroa, dupina guzietako zalbia (3, 45, 6). Azalpena: zalia, 'louche'. Dupina guzietan erabiltzen den zalia. 'Nahasia', adiera ezezkorrarekin. Lhande : touche-à-tout, brouillon, tracassier. Sarean ez da ematen.

F. Qui 'mange à tous les râteliers', qui profite de toutes les situations, sans aucun scrupule (Rey, 705). 'Curieux comme un pot (de chambre)' est peut-être une expression locale.

44. Elhurra murtxatu, milikatu: [mehe ez den andere batez] Itxura guzien arabera, hau ere ezta bizi zardina buztanak murtxatuz eta elurra milikatuz (13, 80, 28). Azalpena: Murtxatu, 'sucer', milikatu, 'lêcher'. Ez da bizi ura edanez bakarrik. Lhande : Murtxatu: suçer, têter, savourer. OEH: Murtxa: succión. Murtxatu: têter, imiter avec les lèvres un enfant qui tête.. Begi-ukaldi, behatze, usna (...) murtxa, milika, ausiki, xurga (...) oro baderamatzagu bat bertzearen ondotik (Etchepare, Buruchkak, 110). Milikatu: suçer. Ez dun gorritu sudurra / milikatuz, milikatuz elhurra ( Elissamburu, Poesias 208). Sarean ez dago.

F: 'ne pas sucer que de la glace', boire beaucoup d'alcool (Rey, 465)

46. Esker $^{9}$ tzarrak merke ukan: [Lisieux-ko Terexa] Bestalde komentuko buruzagiek nahi dute Terecha afruntu eta nekaldietan frogatu. Hortakotz izanen du borietarik esker tzarra merke serora gaiak $(3,140,10)$. Lhande : Esker txar, esker beltz egin daut, 'il m'a fait un mauvais, vilain accueil'. Hemen 'onarpen tzarra egin'. OEH: esker txar, ingratitud, esker tzar egin, acoger mal. Merke, en abundancia. Sarean ez da atxematen.

F: 'faire un accueil de chien' (Rey, 189)

47. Eskuetarik joan: ikusi dut egun batez Athor eskuetarik joana, furria gorrian sartua. Lanak ukan nituen irriak ezin atxikiz. Errana den bezala, errexkiago jasaiten auzoko karguak (13, 108, 14). Eta Su bizia bezain gorri, kara tzar biburrienean, arrunt eskuetarik joana, bots (9, 63, 6) !Hemen: 'sortir de ses gonds'. Lhandek ez du emaiten. OEH : eskuetatik joan, 'on emploie cette formule pour dire qu'un homme divague, qu'il perd la tête. On s'en sert aussi pour dire que l'âge ou les infirmités l'ont rendu invalide' (Duvoisin). Sareak ematen du gaineko bigarren adibidea $(9,63)$. 467).

F: 'perdre la tête', (Rey, 869), 'sortir de ses gonds', apparaît dès le XVI ${ }^{\mathrm{e}}$ s. (ibid.,

9 - H. Duhau, Aupa batasuna, Baiona, 2000: eskerrik ez ukan, 'ne pas (savoir) apprécier'. 
49. Etsi etsian: [Lehengo eta oraiko gora-beherak liburuaren aintzin solasean]) dohatzila beraz lerro guziak etsi-etsian (13, 7, 8). Azalpena: etsi 'désespoir', 'renoncement', 'résignation'. Etsi-etsian, 'à tout hasard' Lhande : Etsipena: désespoir. OEH : etsi-etsian: 's'emploie dans les deux sens différents déterminés par la phrase qui précède: etsi-etsian abian naiz, je suis parti en désespoir de cause, ou bien, je suis parti après avoir longtemps balancé (Duvoisin)'. Hemen, 'que mon texte entier vive enfin, après que j'aie longtemps balancé à l'écrire'. Sarean: etsian etsi zindikatak ere hola tematu badira, eta hori luzaz, bixtan da greba pisu boriek ez direla baatik gelditzen abal gobernuak zerbaiten amor emanez baizik (Herria, 1995)!

F: 'quoiqu'il puisse advenir' (A.Rey, 493), 'en désespoir de cause, après avoir longtemps balancé' (ibid., 149).

50. Etsia eman: [egilearen ama] baizik eta medikuak etsia emana zuela $(13,43$ or, 26). Hemen, 'le médecin avait annoncé que la fin était proche, que le malade était à l'article de la mort'. Azalpena: etsi, 'désespéré', eri etsia: 'malade désespéré'. 'Lhande : 'se résigner à', hiltzerat etsitua da: 'il est résigné à mourir'. OEH: etsia eman: 1) desesperar, resignarse 2) dar fin. Iragan igandean etsia eman zioten eusko Ikaskuntzak Donostian eman duen ikastaroar (Irigaray Larreko) : hemen 'bururatu' erran nahi du.

F : Expression proche, 'être sur sa fin' (Rey, 418), 'être à l'article de la mort' (ibid., 35).

53. Fera-futro joan: [Ney tropako aintzidaria] ez aipa eni apezik! ... doala ferafutro zaia beltza! (13, 23, 15). -Aiaio, fera-futro zoala hastapeneko farrasta lotsagarria, larderiazkoa. $(9,21,9)$. Azalpena: 'sakre bat da'. Lhande : fera, obstacle que rencontre une charrette pour avancer. Futro: juron, 'qu'il aille ... au diable' (306/314). Hemen ere paronimo gisako zerbait aurkitzen dugu. OEH: ferafutre, ferafutro, fuera-futro: en exprs. como ferafutre igorri, joan, despachar con cajas destempladas, ir con viento fresco. Ikus Luzien zuazte fera futre, ene aintzineti, ziek etzirade bün alkharrekikanko beizi (Oihenarte J.: Kaniko eta Beltxina).

F: 'envoyer au diable' (Rey, 311) 'allez-vous faire voir' (ibid., 921).

54. Foltsua, bere foltsua ikertu: gutarik bakotxak iker dezan bere foltsua $(9,34$, 8). Adiera: foltsua, 'le pouls', (pluralean 'tempes') ; ikertu bere foltsua, bakoitzak bere baitan ikus dezan. OEH : foltsu, pultsu, pultzu, poltsu, fultzo, boltsu: 1) pultso. 2) firmeza de brazos y manos. 3) muñeca (St-Jayme). Euskaraz kide bat: badago: bakotxak daki bere berri (E. Bidegain, 31). Bestalde : Kexu kexua bethi, sartu zen eriaren ganberan, eta eriari, berehala, foltsua ikertu zion: Debrientxoa! Zer dun? Zer dun (Barbier, Supazter chokoan)? Hemen Barbierek hitzak erabiltzen ditu adiera zuzenean eta esamolderik ez dugu.

F: 'prendre le pouls de quelqu'un', 's'informer de ses intentions', 'prendre le pouls de quelque chose', 's'informer' (Rey, 763). 
56. Gaitzuru-beteka sakatu: [Charles de Foucauldek "Polytechnique"ko sartzea ez du nahi prestatu) "nundik zitaken bertzela? Hango irakasleek nasaiki eta gaitzuru-beteka sakatzen beren argitasunak eta alfer zonbeiten adimendua laster galkatzen zito-pazka xehenean (13, 86, 36). Azalpena: Gaitzuru, gaitzeru beteka sakatu, 'galkatu'. Lhande: Galgatu, galkatu: 1) remplir en pressant, serrant, tassant. 2) gaver. OEH : Gaitzuru, gaitzeru: 'mesure de quantité pour grains et fruits secs, boisseau, demi-quart d'hectolitre'. Dokumentado desde Leizarraga'.Sarean ez dago.

Hemen : 'gaver, (à pleins boisseaux, à pleins seaux)'.

F : 'Bourrer la cervelle, bourrer le crâne', 'bourrage de crâne' est un synonyme pittoresque de 'propagande intensive et trompeuse' (A.Rey, 269).

57. Galtxagorri ikusi: ikus gorago, akilimarroa ikusi. Azalpena: 'Sufritu, pairatu', 'Galtxagorri', akilimarroa bezala, debruaren izena delarik. OEH : galtxagorri, galtzagorri, prakagorri: 1) 'el demonio, genio familiar: mamarro, galtxagorri y otros nombres sirven para designar a un genio o genios minúsculos de figura humana- de insectos según algunos- que ayudan en sus quehaceres a ciertos hombres. Caben cuatro en una alfilitera y habitan en la del sujeto a quien protegen. 2) que lleva un pantalón rojo'

F: 'souffrir le diable, tous les diables'. 'Souffrir comme un possédé, comme un damné'. (Rey, 755)

58. Garruzeko feiriak bezenbat (ez) iraun: [Foucauld gazteaz]: Bizkitartean beti asean eta betean, noiz arte iraunen du bizi molde horrek ? Ez segur Garruzeko feiriak bezenbat! (13, 87, 23). Azalpena: 'aspaldiko eta betiko iraunpena', Garruzeko feiriak bezala.

F. 'durer (ça ne durera pas) autant que les impôts'. (Rey, 334).

61. Gora pikatuz: Horra nun [bazuela kopeta] beldu zautan lekukoa aintzinean ixtudiant bat, ene adinekoa, eta nolako sanfretean, gora pikatuz $(9,40,39)$. Hitz dautzut araberako nausigo, larderiarekin, eta gora pikatuz mintzatuko dela aleman kargudun handieri $(9,75,31)$. Azalpena: 'gorago izan nahi'. 'Harro izan'. Lhande : Pikatu : 'viser, prétendre, aspirer plus haut'. Gora pikatzen du: 'il a des prétentions plus hautes'. OEHn eta sarean ez dut atzeman.

F: 'avoir des prétentions' (Rey, 768). Synonyme, 'péter plus haut que son cul', avoir des prétentions excessives, tenter d'obtenir ce que l'on n'est pas en mesure d'avoir (Rey, 281).

67. Harenak egina du: [Hitler bere azken momentuetan], lurpeko zilo batean, han zen Hithler zortzi ehun jenderen erdian ... Harenak egina du. Peko errekera eroria, $(13,15,18)$. Azalpena: 'galdua izan', hil-zorian dago. Lhande; OEH; ez dut atzeman. Sarean "klasikoak": Ezinak ezin, harenak egin! / Etxalar galgarri hartarikan zabal/ Hegal bat eta bi hegal, Oraintxet arras aphal,/ Gure urtxoa jautsi- 
galtzen bada gal-/ Hor, edateko gal, gal, gal,/ Duelakoan ahal [Oxobi, Lan orboitgarri zonbait (urtxoa eta ximino)). Hemen, 'c'en est fini de lui'.

F: 'C'en est fait de lui', c'en est fait suivi d'un nom de personne: il ou elle est perdue (Rey, 395).

68. Haro bat altxatu (gabe): Entraalako solas legun, zuriek samintzen dute gaitza. Bertzelako grazia, bihotzetik ateraia den solas gozoak. Berzelako indarra, eriari egina den emaitzarik, den xumeenak. Bertzelako ondorioa, kasik aipatzea balio ez duen eskukalki harek: buburdi hori goraxago ezarriz, ezpain idortu horiek doi bat freskoz goxatuz? Beharrezko gauza hori helmenean ezarriz, haro bat altxatu gabe. Azalpena: 'ahotsa altxatu gabe'. Lhande : Haro: 'Grand bruit de paroles, de cris' ; harotsu: 'braillard' ; harotzar: 'hâbleur'. Hemen 'umilki egin'. $\mathrm{OEH}$ : Haro: 1) bruit rumeur, vacarme, éclat que fait une chose dans le monde. 2) splendor, lustre. Haro egile: alborotador. Haro egin: causar albaroto, dar que hablar. Haro altxatu ez dut OEHn atzeman. Ez dago sarean ere.

F: 'sans mot dire, sans un mot plus haut que l'autre' (Rey, 613). 'Elever la voix': parler avec suffisance ou autorité (TLF). 'Elever un cri': faire monter vers... (TLF). 'Faire la grosse voix' (cette dernière locution est souvent utilisée pour rappeler à l'ordre un enfant) (A.Rey, 922).

69. Hartze onekoa izan: [de Foucauld] hartze onekoa segur bainan zotza bezein alferra $(13,85,18)$. Azalpena: 'Adimen handikoa izan'. Lhande : Hartze, 1) intelligence, comprébension 2) créance: hamar libera hartze ditut, on me doit dix francs. OEH : hartze: 1) créance. 2) accueil: gure auzaphezak hartze idor eta hotza du. 3) Intelligence, faculté d'apprendre. 4) Créancier. Sareak ematen du Etxeberriren beste adibide bat. Aitaso zaharrena miresten baitu bere "papiti" maitearen hartze on, usaiaz kanpokoa [Hazparneko misionestak, 1986].

F: 'avoir la tête bien faite'. 'Être une tête d'œuf': depuis sa première valeur, esprit vide, imbécile jusqu'à la valeur d'après l'américain "egghead", intellectuel. (Rey, 865). 'Être intellectuellement doué'.

71. Hazta handiko gizona izan: [auzapeza] banakien hazta handiko gizona zela $(13,50,25)$. Azalpena: 'Itzal handiko gizona izan'. Lhande : Etre un homme de poids, de valeur, (bazta: poids). OEH : Hazta: 1) poids d'un objet, sa pesanteur. Se dice no de personas. 2) sens du poids. 3) timon de la charrette. 4) anse, manche, mango redondo a diferentzia de kirten. Euskara Corpusa, Ezezaguna : Pentsa nolako harri biburdikatu meta behar ukan duten ezarri, bolako bazta baten atchikitzeko (, Tancarvilleko zubi handia, in Herria, (1959- 7-30)'.

F: 'faire le poids, être un homme de poids' Rey, 739).

72. Hi bahiz eta ni banuk: "Hi bahiz eta ni banuk! Bota beretik eta hordago kanta! " $(9,22,27)$.

Azalpena: desafioaren espresabidea. 'Idée de défi et de surenchère'. OEH : Hi 
bahaiz (eta) ni banauk: a ver quién es más. Sarean ez dago. Bestalde : bi babiz ni banuk, hi handi ni handi. (E. Bidegain, 108).

F: 'jouer à toi à moi?'. Cette expression n'est trouvée ni dans le TLF (expression locale?) ni dans le dictionnaire des locutions de Rey.

73. Hik saka nik maka egin: [hiru Ortzaiztar bipil eta lerdenak] "Santa Katalinaz mandoa saldu zuten eta ederki enganatuak izan ziren. Hain zuzen jakina zuten delako tratulant turko boriek Donibanen izanen zirela. Beti bezala bemen ere denen larrutzen ekarriak... Dakizula diru ebatsiak gibelerat itzuli zituztela Ortzaitze Iruxbehereko biru anaieri! Beharrik! Bertzenaz zer ezpata-dantza ikusiko zuten egun hartan garaztar behatzailek! Ustegabeko ikuskizuna! Hik saka eta nik maka... (13, 113, 5). Erranahia:, 'borroka batean sartu panpaka' adierazteko hitz onomatopeikoa. Lhande, sakatu 1) mettre dans un sac, bourrer, presser 2) faire avaler un mensonge 3) fouler aux pieds. Makatu, bossuer, meurtrir (705 or). OEH : Sakatu: 1) frapper avec qq chose qui n'est pas pointu, avec un corps contondant, piétiner, fouler aux pieds. 2) presser qq chose qui est dans un coffre, emballer, en pressant bien, imposer, ikusi zutelarik Juana erreginak nabi ziotela erlisione berria sakatu,... Etxauzeko jaunak oldartu zitzaizkion ederki -Othoizlari 1961, 345). 3) piquer, piquer le bouf idiaren sakatzea. 4) fourrer, faire croire, faire avaler une bourde, un mensonge, une excuse, eztautak niri holako gezurrik sakatuko.). OEH: Maka: 1) bosse occasionnée aux objets en métal par leur chute ou par des coups violents, tâche marque, empreinte, impression. 2) tâche, marque, impression, empreinte. Bestalde hik maka nik saka (Oihenart. 232. atsotitza). Sarean ez dut atzeman.

F: 'se bagarrer'. Rey indique: 'un coup j'te... un coup j'te', par exemple 'un coup j'te vois, un coup j'te vois pas '( ibid., 259). 'Se battre à toi, à moi' est-elle une expression locale?

74. Hitz erdiaz osoa egin: [predikariak] lehenik agurtu zituen -eta zoin noblekikargudun eta jende handiak, lañoki eta hitz erdiaz osoa eginez. Bakotxari zoakon eta zor zaion ikustate eta errespetu guziarekin (9, 8, 19). Azalpena: 'argi eta garbi mintzatu'. Lhandek ez du ematen. OEH : Hitz erdi: alusión indirecta, palabras veladas, medias palabras. Hitz erdika, erdizka, idem. (, IX, 722). Sarean ez dago.

F: 'parler clair, parler franc, parler net' (Rey, 678).

76. Hitzetik hortzera: [de Foucauld] eta ordu berean, hitzetik hortzera, hasi zen lanean eta zoin lebiatuki $(13,91,24)$. - Dezagun beraz aipha orai berean, bitzetik bortzera, errege borren [Louis XI] manuz hedatua izan den anjelusa (3, 27, 15). Azalpena: 'bapatean, berehala'. Lhande: hitzetik hortzera, immédiatement. OEH: Hitzetik hortzera: 1) continuamente (al hablar); Itzetik ortzera esaten dituzte itz santu eta debotoak (Etxeverria, Devoziozco, 382). 2) al instante, de improviso: Eta itzetik ortzera ara non azaltzen dan Santa Kruz Beobin (Orixe, Santa Cruz apaiza, 120). Sarean: Zer balio dute bitzetik hortzera barreiatzen ari garen butsaren burrengo bitz merke boriek? (Mitxelena, Mitxelenaren idazlan hautatuak).

F: 'tout à trac' (Rey, 880). 
78. Hogoita hamar eta esku (ukan): [de Foucauldek ez Polytechnique zuen prestatu, bainan sartu zen Saint-Cyr eskolan] Hemen ere hogoita hamar eta esku, gure Charlesek nabi zuenaren egiteko. Sartu zen beraz Saint-Cyr burbil, erretxago zaukan aintzindari gaien Eskolan $(13,87,1)$. Azalpena: 'zorte, xantza handiena ukan', mus karta jokoan bezala [ohart joko hoberena dela 31a eta ez 30a). Lhande : esku naiz: j'ai la main. 0EH : Hogeita hamaika (uso propio y fig.): treinta y una en el juego de mus. Artalde baten hoin ongi erabiltzen dakienak ez othe du bogoi-tahameka eta esku herri baten buruzagi jartzeko? (Barbier J, Zupazter chokoan, 38). Ekartzen dudan JB Etxeberriren adibide bera ematen du sareak.

Zergatik Etxeberryk erabiltzen du hogoita hamar eta ez hogoita hameka eta esku? Alta, musean jostatzea ongi badakike.

F: 'avoir du pot ' (Rey, 758); 'avoir toutes les cartes en main' (ez dago Rey-en)

81. Hortzez iguzkiari (egon): [Erromako zizelkariek] Ez zuten alfer tunante egon behar, hortzez iguzkiari, zotzik egin gabe $(13,5,10)$. Azalpena: 'alferkerian beha egon', 'regarder le ciel sans rien faire d'utile'. Lhandek ez du ematen. OEH : Hortzez eguzkiari: vagueando, haciendo el vago. Sareak ematen ditu Etxeberryren gaineko adibide bera eta Mixelenaren beste hau: horrengatik ez uste izan alfer dagola, hortzez iguzkiari, aphez kartsua (Mitxelena L, Hiztegi nagusia, OEH)..

F: 'bayer aux corneilles', 'regarder les mouches voler' (Rey, 67).

82. Iguzkia janari (ukan): - Zer! Petiri Santz etxe santu hortan? Apez horiek iguzkia janari? $(9,11,21)$. - Calvat familian haur andana bat miseria gorrian bizi direnak, ardurenik baitute iguzkia janari (3, 235, 17). Azalpena: 'gosez bizi'. Sinonimoa: 'Petiri Sanz pairatu'. Lhandek ez du ekartzen. Ez dut atzeman OEHn (nahiz OEHn eguzki hitzaren inguruan 50 lokuzio edo hitz konposatu baino gehiago dagoen). Sareak ez du ematen.

F: 'ne pas manger à sa faim, crever la faim, la dalle' (Rey, 393). 'Vivre de l'air du temps'. (Rey, 13)

84. Indiak erori eskuetara: "Indiak eroriko zaizko eskuetarat" (13, 27, 10). Azalpena: 'bat batean eta zorte onez diru anitz irabazi'. Adiera: 'Zorte onez fortuna irabazi'. OEH : Indiak: se dit de grandes richesses. Indiak egin: faire fortune. Sareak ez du ematen.

F: Indiak Amerikak dira bainan ezezko esaera badago : 'ce n'est pas le Pérou' (Rey, 703). Aldekoa delarik, hauxe izan daiteke: 'gagner le gros lot' (ibid., 556).

85. Intan sartu: Bainan, Etzeeri, zer duk golkoan? Kasik erran nabi duk ni baino gehiago estimatzen dukala hire burua? Esplika hadi norapait! Orduan intan sartu nintzan leporaino ene kanore gabeko solas pertoliekin (9, 62, 34). Adiera: littéralement, 'entrer dans le marécage'. 'Se sentir gêné, se faire tout petit, se cacher, rentrer dans le rang'. Lhande : Intha, 1) marécage, marais, bourbier. 2) ornière. 3) sentier. OEH : Inta, inda: 1) sentier, chemin étroit à travers les 
champs. Orga-bide eta inta pullit bati behera beldu zen orai proesionea, kartierean sartzen ari (Barbier, supazter chokoan, 138). 2) Marais, marécage: "Intha zonbait? Aintzira bat? Pasajes erraiten dauku beribilaren jabeak (Etchepare, Beribilez, 91). Bainan intan sartu erran moldea ez dut atzeman OEHn. Sarean ez dago.

Kide frantsesa, kontestuaren arabera: 'se faire tout petit, entrer sous terre, rentrer dans le rang'.

86. Iraziz eta izariz (mintzatu): - Ez gaiten abalaz mintza airerat, ..., bainan deramagun solasa, iraziz eta izariz $(13,72,4)$. - Deramagun beraz solasa mailka, iraziz eta izariz $(9,13,3)$. Adiera: 'zuhurtziaz minzatu'. Hemen, 'parlons avec mesure, de manière réfléchie' (en "filtrant" et en mesurant nos propos). Bi hitzen arteko paronimia ohartzekoa da. Izaria, 'juste ce qu'il faut' ou 'juste mesure', différent de la 'parcimonie'. OEH : Irazi: 1) filtrer, présurer, tamiser. 2) perdre sa clarté (Harriet). 3) arrancar, sacar, arracher: bitz bori ezin eraitzi diot (Lhande). 4) fijar los ojos: begiak iraziz ere, ezin deus ezagut bainezaken (Pradère, Fedearen Propagacioneco, 1906, 129. 5) abîmer, dissiper : herriaren ontasunak irazi (Lhande) 6) urdir el lienzo en el telar 7) laminar, adelgazar el hierro 8) extenuarse. OEH : Izari: mesure, au figuré: mesure, modération, prudence. Izariz: avec mesure et modération. Izariz mintzatu: parler avec mesure. Izariz eman: donner parcimonieusement, chichement. Izariz kanpo: trop, sans mesure. Sareak ez du ematen.

F: 'parler avec mesure, avec précaution, avec prudence'.Il ne semble pas y avoir en français de locution spécifique correspondante à cette locution basque.

87. Jesusian gelditu, izan, egon: - [Lurdeko Bernadette] Noren falta othe da? Errientsak pairu gutichko edo haren argibideak lanhotsu agertzen? Nun eztuen ikasleak kaskoa harripeña bezein gogorra? Dena dela, haurraren jakitatea bethi jesusian gelditu zen goragunerat hegaldatu gabe! (3, 144, 36-37). [Mélanie La Salette-ekoa]: arrunt jesusian dago haren jakitatea (3, 236, 2). Azalpena: Lhande : Jesus, 1) l'Homme-Dieu. 2) premier mot que l'enfant apprend à articuler, à lire, etc... d'où le sens de "début". Oraino jesusian gira lan borri buruz, nous sommes encore au commencement de notre tâche. OEH : Jesus: 1) interjection qui exprime la surprise ou la contrariété 2) en contextos negativos, ni palabra (pas question) non gauza ez geran gerenez, Jesus bat esateko ere bear bezala (Aguirre, Eracusaldiac, 508) 3) abecedario, début. Egia erran, euskara ez dago jesusean" (Herria, 13-4-1961) 4) un moment, jesus bat: un moment. Sareak ez du ematen.

F: 'En être au commencement' et voir aussi les expressions 'en toutes choses, il faut commencement'.' En toutes choses il y a commencement' (Rey, 224).

89. Karba bera adiarazi: - Familiako adixkide batek ere De Comet abokata karba bera adierazten diote $(3,50,31)$. - Aldi buntan ere erakusten du erretorak bere bihotzeko arrangura-mina, bethiko karba bera adiarazten duela (3, 106, 14). Azalpena: 'tehenta', "beti karba bera", 'toujours le même refrain', (Lhande, 595). OEH : Karba, garba: 1) gerbe, ogi garba, azaua: gerbe de blé. 2) avena que se deja sin trillar y que se da a los bueyes cuando labran. 3) instrument à broyer le chanvre, 
le lin, kharba: instrument pour carder le lin. Au figuré, kharba: refrain, rengaîne. 4) garba: fleur de noyer, de chêne. 5) couverture d'une grange, toit grossier. 6) lo garba: sommeil léger. Oroit, dena den, Oihenart (1657), Lau karbarien eresia. Sarean adibiderik ez dago.

F: 'rengaine', 'propos toujours répété et qui lasse'. TLF informatisé : '(Avoir, dire) toujours la même rengaine, le même refrain, la même ritournelle' . Rey ne les rapporte pas.

90. Kaskoa pilda darian ezarri: obore soberakinek plomuan zen kaskoa pilda darian ezartzen?" (13, 62, 29). Hemen,' un trop plein d'honneurs peut-il transformer (en chiffon) une tête jusqu'alors d'aplomb' ? Azalpena: pilda: 'piltzarra'. Darian: *jarin aditza ('couler, jaillir') piltzarra burrustan ezarri. OEH : Pilda: 1) vêtements, effets, linge, s'emploie dans ce sens au pluriel. Se dit aussi de haillons, linge et étoffes, déchirés. 2) en phrase négative: rien ez da phildarik sobratu (Pouvreau, Philotea, 308). 3) terme de mépris, femme ou bomme de rien. 4) Bizkaieraz, feo por naturaleza o por su vestimenta. Sareak ez du ekartzen.

F: ici, 'avoir la grosse tête, la tête comme une pastèque' (Rey, 868). Ou bien, plus généralement, 'perdre la tête', cf. 'ça va pas la tête' (ibid., 867).

91. Kausitu (norbaiti, deneri) kausitu: [Attor Heletako erretorak], apez borrek badik bedadura ta goxotasun berezi bat solastiar lagunen argitzeko. Bai eta ere alegia deus ez- deneri kausitzeko bere ateraldi pollitekin (13, 112, 21). Hemen, 'plaire à tous, convenir à tous'. Adiera: 'norbaiti atsegin izan'. 'Norbaiti plazer egin. Lhande : Gagner les bonnes grâces de quelqu'un, complaire à quelqu'un, contenter quelqu'un: kausitzen dakote, ils en font à son gré, ils lui plaisent. $\mathrm{OEH}$ : Kausitu (con complemento en dativo, auxiliar transitivo): complaire, se rendre agréable auprès de quelqu'un: Leonek nausiari khausitzen daka eta bunek maite du. Kausitu dio (Laffitte, Grammaire, 819). Hari khausitü nabiz, indarra bortxatzen. Usuenik, kausitu aurkitu-ren sinonimoa da beste adiera batekin. Ad. Jende guzia miretsia zagon, eta jaun merak erraiten zioten orori: gaitzeko gizon babila dugu berriko mirikua; mina berehala kausitu daut eta berehala sendatu (Laffitte, Murtutz eta bertze). Sarean ez dut aurkitu (kausitu) norbaiti kausitu.

F: 'trouver grâce aux yeux de qq'un' (Rey, 472).

92. Kondu, penitentzia kondu: Kurutzada deithu gerla saindurat abiatu baino lebenago bere armak benedikatzen zituen [Saint-Louis-ek] otre Dame Des Vertus deithu elizan eta gero unthusik, penitentzia kondu, eremaiten zuen tropetako bandera Notre Dame de Paris Katedralerat. Azalpena: hemen,'penitentziaren egiteko' 'au compte de la pénitence. Erraten da ere, amodioa kondu, 'au compte de l'amour'. Lhande : considération, cas, soin, charge. OEH: Kondu, kontu: atención, consideración, tomar en consideración. (Como secundo miembro de complemento; indetermindado con valor adverbial) zer zabiltza zu emen, makilla eta guzi? Ardi kontu! (Txirrita, Txirritaren bertsoak, B II 99)Sarean ez dago.

F: 'au compte de', 'sur le compte de', fait plutôt partie de la locution 'mettre sur le compte de...', 'à son sujet', 'sous sa responsabilité'. (Rey, 228). 
95. Lau hatzetarik pindarra jarin: [Marie-Gabriel anaia]: bere lehen ikasgoak egin zituen kartsutanezko bidetan, chuberrotarrek dioten bezala" lau batzetarik pindarra zariola $(3,183,29)$. Azalpena: kide frantsesa: 'faire feu des quatre fers'. OEH : Hatza: 1) doigt 2) pied des bêtes,.. Se dit exceptionnellement des personnes 3) trace imprimée sur le sol par des pieds, vestige. 4) prurit, gale. 5) bord inférieur d'un vêtement. Sarean ez dago.

F: 'faire feu des quatre fers' (Rey, 402)

96. Makila hautsia (haien) artean (ez) sartu: [Jean le Bon Frantziako erregea preso Inglaterran, baldintza onetan baina halere] ez gaiten beraz borien artean (Frantzia eta Inglaterra artean) sar makila hautsiarekin $(13,18,11)$. Hemen, ez gaitezen sar nola nahika holako auzian, baina bai mesfidantza handienarekin -beraz makila azkar eta osoarekin- zeren bi presunen arteko gatazka pizten baldin bada hobe da haien artean makil oso batekin sartzea ezen ez makil hautsi batekin. Azalpena: figuratiboan, 'ez heiei fidatu'. OEH : Makil: bâton. Makil autsiekin ez oien tartean sartu, no te fies de ellos, litm: no te metas en ellos con palos rotos (Azkue, Euskalerriaren Yakintza, III, 290), eman zaite zu bien artean makbila bautsiarekin, (Etxeberry, Zeruari, 178). Sarean ez dago.

Frantsesez ez dakit parekorik baden.

97. Mandoak adartuko dira lehenago: - Horiek guziak utzi beharko! Ez arraiz! mandoak adartuko dire lehenago $(13,21,18)$. - Mandoak adartuko dire nik jakin gabe noizez geroz ginen gisa hortan kusituak $(13,107,14)$. -Zoaz funtsera eta obartuko zira jende perfektik eztela mundu buntan. Mandoak adartuko dira bolako bat agertuko den baino lehen (9, 72, 18). Azalpena: 'sekula ez gertatuko', 'ezinezkoa izan'. Lhandek (711) ematen du edo mandoak adar, coûte que coûte ( (Zubero). Sarean (Euskal lokuzioak sarean) ematen dira hiru adibide, hiruak JB Etxeberrirenak. OEH : mandoa: mule, mandoa nor duk aita? Bortutik behorra ederrena (Oihenart, Atsotitzak, 311). Adar: corne, bainan mandoak adartu ez dut atzeman OEHn.

F. 'quand les poules auront des dents', 'quand les poules pisseront' (A.Rey, 763)

98. Mihi peko zaina ausarkian trenkatua : - [Lacordairen ama] begi pindartsuen jabe, mihi peko zaina ausarkian trenkatua, $(13,61,8)$. - Irakurlea ohartua ditake mihi-peko zaina ongi trenkatua zuela misionest gazteak, $(9,12,6)$. Kalakaria, mihi azpiko zaina arras moztua balu bezala. Adiera: 'Kalakaria', 'mihia sakelan ez ukan' (Euskal lokuzioak sarean). Lhande : Mihipekoa ongi pikatu zioten, on lui avait bien coupé le fil de la langue (se dit des personnes qui parlent facilement). OEH : Mihiazpiko, minazpiko: frein de la langue. Trenkatu: couper, couper un fil, une corde en la tirant de deux côtés. Mihia trenkatu: mihia trenkatu eta aurthiki zuenaz gero (Pouvreau, Philotea, 439). 'Euskal lokuzioak sarean'-ek ematen du nik atxikitzen dudan Etxeberriren bigarren adibidea.

F: 'avoir la langue bien pendue, ne pas avoir la langue dans sa poche' (Rey, 534). 
99. Milako bat ... (ez) izan: - [Lacordaire entzunez] ezta milako bat beraz jende osteak espantituak egoiten baziren haren suzko mintzaldieri beha... (13, 64, 21). . Ezpaita milako bat beraz, denbora laburrez, egin arazi bazuen, eta azken arditaraino pagatu, obra espantagarri hau..." (9, 22, 8). - Ezta milako bat beraz harritu balinbada aphez gaia zuen guzien aintzinean tuntik ez atheratzerainokoan $(3,97,16)$. Azalpena: 'ez da harrigaria', 'ils n'ont pas fait merveille même s'ils ont fait cela'. Lhande : cf: erdaraz, milako: milagro. Ici, il n'est pas étonnant que. OEH : Milagro, mirakulu, mirari: miracle. Ez da (zen) milagro: no es de extraordinario, no es raro. Ez da milagrorik/ni laster galtzea/aisa merezi nuen/bertan urkbatzea (Lakarra, Euskal baladak, 221) Sarean ez dago.

F: 'ne pas (falloir) crier au miracle si' (Rey, 600).

100. Moltsan kukuso izan: [Abbé Pierre] Bainan azken kapitulu huntan beharrena falta du muñi-muñi delako sagu kafira baitezpadakoa. Moltsan kukuso eta portafuilla seko, turrindua egunetik biharrerat, deus mutzitzerat utzi gabe (13, 104, 31). Adiera: 'moltsa hutsa'. 'Moltsan limarrik ez'. Lhande: moltsa: bourse. Kukuso: puce, moltsan kukuso izan". OEHn ez dut atzeman. Beste adibidea: hamabi bizibide, hamabiru gosebide: behar baino maizago moltsan kukuso (Léon, 1927, 1960) Euskal lokuzioak sarean.

F: 'être à sec' (Rey, 827).

101. Muñi-muñiz azkar izan: [de Foucauld bere liotinant galoinak ukan eta lagunei afari bat opatzen die] Muñi-muñi azkar denak laster atxemaiten adixkideak $(13,87,29)$. Azalpena: 'aberatsa izan' Muñi-muñi: dirua. Lhandek ez du ematen. OEH: Muñi-muñi: onomatopeia enpleada para referirse al dinero. Guziek on baino hobe dirua! Denek eskas muñi-muñi ( Salaberry, Herria 13-5-1965). Sarean ez dago.

F: 'riche comme Crésus' (A.Rey, 803).

103. Mutur saldak merke egon: - Handik harat hitz idor, esker gaichto, mutbur saldak merke dagotzi Labouré familian (3, 81, 28-29). - Haren aita berriz esposatu baitzen, amaizun minkor, bihotz idorreko batek, haur gaichoari emaiten diozka ausarkian eta tole mutbur salda eta zaflako mingarriak (3, 236, 17). Azalpena: 'mutur', 'aurpegi', Lhande : muthur egin: faire la moue. Gotzon Garate, Erdarakadak, 150 : Mutur-salda, mutur-saltsa: riña, riña entre esposos, mutur saltsa egiten du junto a koskan da, kexu da, kexatu da, $\mathrm{OEH}$ : Erran dute aroaz bertzerik bazela hotzik, eta mutur-saltsa frango merke zela hango ostatuetan' (Herria, 21-41960).

Sarean badago Etxeberriren beste adibide bat.

F: 'soupe à la grimace', accueil hostile d'une épouse acariâtre et querelleuse (Rey, 845). 'Faire la tête'.

104. Norbaiten ixilik zerbait egin: hain xuxen banintzin bortz liberako zilarra. Amak emana, aitaren ixilik $(9,41,10)$. Azalpena: 'nekork jakin gabe'. Lhande: 
A l'insu de. OEH : Ixilean: 1) en secreto. Precedido de genetivo, a escondidas de. Andria ixilixan, kotxia erosi zeban (Elexpuru, Bergara aldeko lexikoa). 2) en silence, en secret. Ixil-ixilean, en secret. Sarean ez dago.

F: 'à l'insu de, ce qui n'est pas su, à mon insu, ton insu... etc' (Rey, 510). 'En secret, en cachette, à l'insu d'autrui' (ibid., 827).

105. Nor gira gueneko izan: [bi haur]: ez dira segur nor gira-gueneko seme alabak!. Adiera hitzez hitz 'ce ne sont pas des enfants de parents fanfarons (euphémisme pour indiquer des parents d'une classe sociale supérieure). Adiera: 'harro izan', 'ahobero', 'hamalau', 'handiputz', 'harroputz' 'fier izan' etb (Sinonimoen kutxa). Lhande : Nor gira gu? Qui sommes-nous? (expression de fierté, d'orgueil). OEH : Nor gara gu, nor gira gu: orgueilleux, handius, handikari, harro, txüt, nur-gira-gü (Z). Bebin iduri zuten Clemenceau eta Barthou bi ministro "nor gira gu?" oro larderiatsu nabi lituzketenek oro erbautsi behar zituztela (Hiriart Urruty, Euskalduna, 23-3-1909).OEH : Nor-gara-guka: fanfaroneando. Bainan nor gira gueneko izan lokuzioa ez dut atzeman OEHn, ez eta sarean.

F: 'être vantard, fanfaron, orgueilleux'. Ikus 'se croire sorti de la cuisse de Jupiter' (Rey, 278).

106. Ohoreak-ohoratei: (Foucauld anitz ohoratua izan zen] oboreak ohoratei, ezta Charles ibiliko larruak atxik-ahala hantua baina bai beti hartan umil eta goxo (13, 92, 23). Azalpena: 'ohoreak-ohorategitik (ohorategian)', hitzez hitz 'laissons les honneurs à leur place (et passons à autre chose)'. OEH : Ohore: empleado frecuentemente en plural. Honores, demostración que se hace a una persona en reconocimiento de su mérito o categoría. Ohoreak-ohoratei ez dut atzeman OEHn ez eta sarean. Adibidez, Piarres Xarritonek oroitarazten du erranaldi hau, gezurra gezurtei, 'le mensonge est mensonger'... (eta arlo semantiko berean atsotitza gezurra beti xanku, G. Garatek ez duena ematen).

H. Duhauk dio 'ohoratei' 'ohorategitik' etortzen dela, beraz 'ohoratei' dela "ohorea" hitza ablatiboan.

F: 'être au-dessus des honneurs', 'quoi qu'il en soit des honneurs' bainan ez dago baliokide zuzenik.

109. Onez-onean izan: - [lepradunei], horra non beldu zaioten apez gazte bat, onez-onean, bere baitarik etorria $(13,58$, 28). Hemen, 'adixkidantza osoan', 'jarrera hoberenean'. - [Hiru Irisartar bortitz] onez-onean hautuzko gizonak bainan gutien ustean, sudur pintzak kitzikatu gabe odolak irakitzen $(13,113,12)$. Hemen, 'une onean zirelarik gure irisartarrak jende onak ziren, bainan halere laster haserretzen'. 'Quand tout va bien'. Azalpena: Onez-onean: 'bihotz eta gogo onean', norbait jarrera onean izan. Lhande : De bonne foi, en toute amitié, en bon accord. Hemen 'de bonne humeur' bainan ere, 'quand tout va bien'.. OEH : Onez-onean, on-onean, onez-onera: volontiers, de bon gré, on onean, pozik, maita, (Itun berria). Lokuzioak sarean, Onez-onean gobernamenduko gizonekin bakean bizi (Hiriart Urruty, Mintzaira, aurpegia, gizon). 
F: 'de bon gré, de bonne grâce', 'attitude aimable, grâcieuse'. 'Bonnes grâces', être dans les bonnes grâces de qqn. Voir la différence avec 'bon gré, mal gré'. (Rey, 472).

110. Opila hozterat utzi gabe: orai beretik erranen dugu, opila bozterat utzi gabe, mintzatzale pollita zela $(9,37,13)$. Azalpena: 'berehala'. Lhande : opila, tarte de maïs, gâteau de pain. Bainan opila hozterat utzi" ez du ematen. Aldiz, opil hitzarekin beste lokuzio hauek badaude: Opila ogia egin dik" eta bere kide frantsesa hauxe da ,faire sa pelote' (Rey, 699), eta Bihotza opildua dut, 'j'en ai gros sur le cœur' (ibid.). OEH : Opil: galette, gâteau, petit pain de blé ou de maïs. Nork bere opilari ikatza (Refranes de Garibay).

Amak irin balu, ogia egin balaidi (Oihenart, Atsotitzak, 30.). OEHn opila hoztera utzi gabe ez dut atzeman.

Sarean atxematen da JB Etxeberriren eman dudan aipamena.

F: 'sans laisser retomber le soufflet'. 'Battre le fer quand il est au chaud', exploiter une situation sans attendre (Rey, 403).

111. Orratzetik hari: [Decourtray kardinaleak egin bisita baten ondotik] eta bemen, orratzetik hari, Decourtray jaunak eman xebetasunak" (13, 81, 30). Azalpena: 'solasa segituz'. Lhandek haritik orratzera ekartzen du. 'en suivant le fil de la conversation'. OEH : Orratza: 1) aiguille, oil de l'aiguille. 2) Broche 3) aiguille d'horloge, boussole, montre.- Sorgin orratz: libellule. - Haritik orratzera: 1) De propos en propos, une chose en amenant une autre. 2) Sans rien omettre, avec les moindres circonstances. Nabi dut dena aditu, eta erran ditzadan baritik orratzerra (Harriet). Sarean: eta han, jarririk, eletik-ele, orratzetik bari, oren laurden bat barne, Ellandek bi dupa arno erosi Pettani' (Léon, Alegia deus ez. Alegiak eta ipuinak).

F: 'de fil en aiguille' (Lhande), 'en passant progressivement d'une chose à l'autre dans les propos' (Rey).

113. Paramola (ez) erabili: [apezgai batek bisitaldiak egiten zituen Baionako ospitalean] ikustekoak baitziren baren pasaldien ondotik, eri gaixoen begitarteak bozkarioz argituak. Holakoa zen etorkiz, sortzez, goxoa eta maitagarria. Eta elea ongi erabiltzen paramola alferrik gabe $(13,91,6)$. Azalpena: 'Kalaka', 'pergario', dena parabola da gizon hori. Lhande : cet homme ne fait que parler. Hemen, alderantziz, 'sans effet inutile, sans bavardage'. OEH: Parabola: 1) relato alegórico. 2) flux de parole en vue de faire valoir sa thèse, son désir etc. Bavardage. Ez dut osorik hartu baten parabola/ erdaraz mintzo baitzen, berak jakin nola (Xalbador, Odolaren mintzoa, 179). 3) comparaison: zahar gazten arteko parabola (Bordel bertsularia, 105). 4) chiste, anecdota: aik edan eta paramolak esan eta soseguz egoten dira tabernan (Anduaga, Aitonaren Uzta, 76). Sarean ez dago.'

F: 'et patati et patata',' parler comme un moulin, comme une crécelle' (Rey, 688) 
114. Pasa errexa izan: Ene bizi guzian bermatu naiz Jesu-Krichto gure Jaunaren Imitazioneko liburuan kausitzen diren lau kontseiluen segitzerat: ... ahal oroz lebia zaite bethi pas'erretcha izaiterat ... (3, 224, 8). Azalpena: jateko eta beste humilak, 'xuhurki bizi', 'facile à satisfaire', se contentant de peu'. Lhandek ez du aipatzen. OEH : Pasaerraz, pasaerrex: el que puede pasar con poco, sobrío en comer y beber. Naizen bezalako sagu/ ttiki-ttiki pasa-errexal izan daitekeia karga/ etxearentzat batere? (Goyhetche, Fableac edo aleguiac, 98). Arreglárselas: berekin pasa, besten gaitzak ützi (Etxahun, 666).

Kide frantsesa 'se contenter de peu' izan diteke.

115. Patarraka egin, hasi : Horra beraz nun etorri den orboitzeko eguna. Beha bunat! errege bidetik seminario berriari buruz inobreka badohatzi oinezkari eta bertzeak. Denak oibuka eta patarraka, Hoxta kaskoan lertsunak bezala. Hauxe da jendaldea! (13, 109, 32). Azalpena: 'oihu eginez'. Lhande : haut cri pénétrant d'appel, d'angoisse. Patarrakaz dago: il pousse des hauts cris. Ce mot est souvent accompagné du mot oibu, cri ou orro, mugissement, nigar, pleur. Orro patarraka hasi zen, il commença à pousser des hurlements. OEH : Patarra, patara: haut cri perçant d'appel ou d'angoisse. Gure orro patarrak dituk/hemengo ihortziriak (Gazteluçar B, Eguia catolicoac, 161). Pattaraka, grito : hil zen pattarakaz (Hiribarren, Eskaraz eguia, 858, 14. Sarean ez dago.

F: 'jeter, pousser des hauts cris' (Rey, 271).

118. Petenta, bortakoari petenta (bezala) egokia izan: [de Foucauldek bere liotinant galoinak izan ondoan] badoako bortakoari petenta! Karia bortarat bere urrezko bi xerrendak hein bat lorioski ospatu zituen sekulako otruntza pagatuz bere lagun guzieri (13, 87, 26). Azalpena: norbaiti ohorezko galoinak edo xingolak egokiak izatea urde bati bezainbat (norbaitez trufatzeko). Hemen,' les galons lui vont aussi bien que les chamarrures au porc'. Lhande : Badoako zerriari petenta, ça lui va comme des pendants à un goret. OEH : Petenta: 1) pendiente 2) torpe, algo bruto, indécis, embarrassé: Khen hortik othoi gizon petenta ((Lhande, ibid). Zonbait urthe hotan badira jende petenta batzu, (...) Napoléon denborako beztimentak barturik emaiten badira Sakramendu Sainduari gorthe eta obore egiteko (Herria, 27-6-1957, 3).

F: 'ça lui va comme un tablier à une vache, à un cochon', ça ne (lui) va pas du tout, (ça lui va) ridiculement mal (Rey, 17).

119. Pikoa zauriaren gainean eman: [soldado aleman batek preso belgikano ihes emana bati], zauriaren gainean pikoa erraiten dio, boza muzikatuz: hizan bezalako zirtzil ezdeusa! Ihes egin nahi? Tokiak hustu? Zer karietarat? Hireak eginak baituk oraiko buntan! $(13,30,12)$.Hemen ' gaitzitu', 'ukaldia zauriaren gainean berriz eman'. Lhande : piko: 1) figue, 2) ressources, travail, 3) blessure, mot blessant, offensant. Pikoan eman, régler, ajuster. Piko bat eman, lancer une pique. OEH : Piko: taille, entaille, Zaurin gainen pikoa, un coup de taille sur la vieille plaie (Oihenart, Atsotitzak, 425). Hori alfer-lana litzateke, eta zauriaren gainean piko (Mitxelena, Euskal Idazlan Guztiak, 43). Klasikoak armiarman: bebinik bebin aitortu 
behar da ederki badakitela jaun boriek zauriaren gaineko pikoaren ematen (Zerbitzari, Artho-xuritzetan).

F: 'enfoncer, remuer, retourner le couteau dans la plaie': faire souffrir qqn en évoquant ce qui lui est très pénible, en ranimant une douleur (Rey, 265). 'Mettre de l'huile sur le feu' (ibid., 502).

120. Piru hortakoa (ez) izan: Hor dabiltza [mundutarrek] noiz eta nola izanen diren nagusitasunez gaindituak, jenden abomibietan handizki aipatuak. Den gutienaz erranen dugu etzela piru bortakoa aitoren seme gaztea (13, 94, 14). Adiera: 'ez holakoa izan', ne pas être de cette étoffe. Lhande : Piru: tout brin plus ou moins long et délié qui se détache en forme de fil. Au fig. phiru oneko gizona, homme accommodant. OEH : Piru: brin de fil, de soie. Au figuré, on dit: phiru oneko, tzarreko gizona, homme accommodant, de caractère facile ou difficile, retors. Gizon piru abulekoaren ateraldi hori (...) buru guti eta hura beroa (Hiriart Urruty J, Aurpegia, in Euskalduna, 17). Sarean ez dugu aurkitu...

F: 'être de la même étoffe, d'une autre étoffe', avoir des qualités différentes, généralement supérieures, ou des qualités semblables (Rey, 381).

121. Pittika haizatzerat (bidali, igorri): jakintsunak atrebituenak bermatu ziren leben prima irabazi beharrez. Doatzila denak pittika haizatzerat, antzara ferratzerat. Hurbiltzen da l'abbé Pierre bere sotana zabarra berrestan, pika haizatzeko mamu bat iduri eta begiak hets-ideki artean galde guzieri arrapostua xuxen" $(13,106,3)$. Hemen, 'qu'ils aillent se faire voir ailleurs, aillent au diable'. Adiera: allez vous faire voir. Lhandek ez du ematen. OEH : Pittika: chevreau. Gan bedi pittika haizatzerat (Herria, 29-10-1959). Sarean: Pittika haizatzerat igorri, bidali: solasa edo harremanak haserrez hautsi.

F: 'aller au diable, aller se faire voir, se faire fiche', servent généralement d'invective. (Rey, 16).

122. Populu, eman zerbait populu: [Soubelet kalonjea] Denak bazituen: kantaria, musikaria, hiztun arradoa, jende hartze gozoena... ardurenean bederen. Behielako Tartarin haren gisa: kantuz guziaz xaramelatuz eremaki. Baitezpadako kopeta eta bekokia bura populu!" $(9,65,16)$. Adiera: 'gainera, bestalde'. Lhande : Dotzena bat sagar horrekin ematen dautzut madari bat populu. OEH : Populu: 1) le peuple. 2) s'emploie adverbialement: donner par-dessus le marché, popülu eman, donner en sus de compte, si on donne treize au lieu de douze, le treizième est populu. Behar huen beraz ene dirua eman irabazira, eta nik, ethortzen nintzenean, enea populurekin altxatuko nian (Duvoisin; Bibliaren itzulpena, Mt 25, 27). Adiera horrekin ez dut sarean aurkitu.

F: ' par dessus le marché', littéralement en plus de ce qui a été convenu (Rey, 581).

123. Prenda pollita izan: [Thomas More Henri VIII erregea konbertitzeko nahian] lege da ala ez enseiatzea? Segurki baietz baina deus egitekorik jaidura 
tzarren esklabo den ibizi, prenda pollitarekin" $(13,79,22)$. Hemen, 'être un sacré, joli phénomène, un drôle de phénomène'. Azalpena: 'debrien animalia'. Lhande: Prenda: gibier. OEH : Prenda: 1) objeto balioso, pesetea galduta prendarik artu ez (Arrese Beitia, Ama Euskeriaren..., 281. 2) mercancía 3) emazte hori zer prenda (Lhande, 'quel gibier'. 4) Garantía. 5) Cualidad, virtud, onek merezi baditu onra guziak bere prenda handiak gatik (Moguel, Confesio ... eracasteac, 1800, 242). Sarean ez dago.

F: 'quel oiseau, drôle d'oiseau' (Rey, 655).

124. Putz, bihotza otso putza bezala hantua ukan: Badixit beldurra bibotza otso putza bezala hantua nuela gogoari emanez ingurune bautako jauneria guziari mintzatu behar nintzala. Bazautxu? tipus tapan obore guziak betan! (13, 109, 14). Azalpena: 'harro, urguilutsu izan'. OEH : Putz: 1) souffle: Putzak pizten du bela eta bai hiltzen ere (Oihenart, Atsotitzak, 401). Aizez izorra zedina putzez erdi zedin" ibid. 542, ce qui est superficiel le reste. 2) Pedo, especialmente sin ruido: uzkerra dena irri, putza dena aharra (BN-Cize). Se dice de personas medianas que quieren darse tono: putze izan eta puzkerra nai (Inza Naparroako Euskal esaera zarrak, 267). Abereekin erabilitako esaldien artean : zakurraren putza: gauza ezerreza, orrek ez dik balio/ zakurraren putza (Txirrita, Bertsoak 57). Orri ta astuaren putza, igualak (Elexpuru, Bergarako aldeko lexikoa) Otso putza bezala hantua izan ez dut atzeman OEHn. Ez da sarean kausitzen.

F: être gonflé d'orgueil', 'fier comme un pou', 'orgueilleux comme un pou', 'comme un paon'. On trouve aussi des locutions verbales, 'se pavaner, se rengorger comme un paon, ou faire le paon' (Rey, 674). 'Vouloir péter plus haut qu'on a le derrière (le cul)', avoir des prétentions excessives, 'péter plus haut que son cul' (attesté depuis 1640), (Rey, 707).

126. Sanfret, sanfretean erran: [Australiar bidaiantea eta filosofian jakintsuna] Dena dela abiatu dugu delako jauna Australiarat buruz hango gorabeberez izpirituaren hobeki argitzeko. Itsas untzian itsasoari beha dago, bastingari kontra emana. Hurbiltzen zaio mariñel euskaldun bat. Hein bateko sanfretean jakintsunak itsas-gizonari: ezagutzen duzu filosofia? "Ez limarik ere! Zer lumetakoa da ibizi hori"? (13, 19, 11). Azalpena: 'Kopetarekin erran'. Lhande : 'dire avec aplomb, avec audace' bainan ere 'avec du toupet'. OEH: Sanfret: aplomb, audace . Syn: bekhokia. Erran zautan sanfret handirekin (Ducq, Erroma eta Jérusalem, 384). Nolako sanfretean: con que audacia, con que garbo, dailu batekin ari zen lapar mozten eta nolako sanfretian! (Otoizlari, 1970, 57-58), 16). Euskararen corpusa sarean: Apheza mar mar mar othoitzean liburutik! /zer sanfreta baatik! Horrek badik burutik! / Gazte bat aldiz kantuz, kobla eta errepika! / Uste duk kantuz ariz joanen dela mekanika?/Andereño uli badoakote aldizka beharri ziloan jotzera bere chirrinka (Laffitte P, Alegia... deus ez! Karrosa eta ulia, Gure Herria, 1954, XXVI, 371-372).

F: 'dire avec aplomb, avec audace'. 'Avec un culot de capitaine'. 'Avoir un sacré culot'. 'Ne pas l'envoyer dire à quelqu'un', dire soi-même sans intermédiaire. (Rey, 318) 
128. Sasitik berroan sartu, joan: - [Thomas More eta HenriVIII] baren
denborako Henri VIII Angleterrako erregea gaizbide, eskandala gorrian bizi zen... zer egin [Thomas Morek] ? Zazpi abalak egin zituen eta molde guzietarat bermatu saindu gaia nausiaren konbertitzeko. Debaldetan! Sasipetik ateratu orduko berroan sartzen" $(13,79,20)$. Hemen, ihizia sasitik atera orduko berriz berroaren aterpean sartu. ,Egoera berdinean edo txarragoan jarraiki'. - [Paulo Bitxintxo -Saint Vincent-de-Paul esklabo hartua] tratuak ez du anitz luzatu: idek aboa, ikus bortzak, mia sabetsak, hazta zango besoak, ... eta borra presoner dohakabeak, sasitik atheratuak berboan sartzeko, nagusi salbai batzuen meneko eroriak $(3,52,18)$. [ Cestac]: " (hastapenean, matematika deithu kondu jakintza zimur eta zuko heien erakasle. Gerochago-sasitik berhorat!- gu bezalakoa laster lotsarazten duen "filosofia"- delako buzoka basaren biphilzaile (3, 120, 33). Azalpena: Lhande : berro, hallier, haie épaisse, naturellement formée de ronces, épines, arbustes. Sasi: fourré, hallier épais, broussailles, buissson. Sasiak beharri: la haie a des oreilles (F: les murs ont des oreilles). Sasi eta berro sinonimo dira. Beraz, sasitik berrora joateak erran nahi du 'gaiztotik gaiztora' joatea. OEH : Sasi, fourré, hallier. Zenbaitek arantzari, masustak ematen dituenari sasi deitzen dio. Sasiren esanabi arrunta orokorragoa da (Elexpuru, Bergara aldeko lexikoa). Usado en locuciones y expresiones proverbiales. Don Carlos Angleterran zen ihesi joana... Laster obartu zen ordean egina zuela sasitik berrorat ( Gure Herria, 1935, 313). Sarean ez dago.

F: 'aller de mal en pis'. 'De plus en plus mal, en s'aggravant' .Rey, 573). 'Tomber de Charybde en Scylla' (Rey, 169). Le gouffre de Charybde est voisin des rochers de Scylla dans le détroit de Messine (l'Odyssée). Voir la déformation apportée par Balzac dans Splendeurs et misères de courtisanes, 'de caraibe en syllabe'.

131. Set egin: [de Foucauld) boriek guziak holatsu, dezagun aitor arras kartsuki egin zuela Charlesek bere komunione handia. Zonbeit egunez bederen utzi zituen, set eginik, bere usaiako josteta, abusagailuak (13, 86, 12).

Hemen, 'dire adieu, renoncer à ses habitudes'. Azalpena: Lhande : Set egin: 1) échouer, renoncer à un espoir, set eginik irabazteaz, utzi du jokoa. 2) dire adieu. 3) se perdre, se gâter, se corrompre. OEH : 1) renonciation déterminée par la conviction de l'impossibilité acquise après divers efforts tentés et par désespoir. Set eginik utzi zuten Babeleko dorrea egitea", Voc. BN. 2) faire fiasco, par manque de force. 3) Rompre la branche qui était depuis longtemps sur le point de se casser rompt à la fin. 4) set egite, (familier): mourir. 5) Se perdre, se gâter, se corrompre. 6) Dire adieu. Ez da sarean kausitzen.

F: 'dire adieu à qqch', y renoncer'. 'Tu peux dire adieu à ta nomination! ... lui dire adieu!' (Rey, 6).

133. Sudurra mizkindu: [abbé Pierre ezagunaren aitak igande guziz pobreen biloak mozten] 'ez ote du karitatezko obra horrek balio, sobera maiz sudurra mizkinduz, esker gabe batean emaiten den sos peto bura? (13, 104, 21-22). Hemen, hitzez hitz 'en fronçant le nez'. Adiera: Lhande : Miskina, sinu, grimace. Miskindu, devenir grimacier (ibid.). OEH : mizkindu: 1) apocar, disminuir, aise mizkint zitaken gai ospetsu bori (Herria, 27-2-1958). 2) devenir gourmand (Lhande) mizkintzen ari da ume ori (comunicación personal de L. Villasante). 3) devenir 
grimacier (Lhande): medikuak eskuratzen ditu (zigarroak) erbietan itzulikatzen eta sudurra mizkinduz usaindatzen (Gure Almanaka, 1963, 6). Sarean JB Etcheberryren adibidea emana da.

F. 'allonger le nez, faire un long nez, son nez s'allonge, tordre le nez' (Rey, 631, 632).

134. Sudur-peko xiloa beti zerbaiten galdez: Sudur-peko bura beti zerbaiten galdez $(13,85,20)$. Azalpena: sudurpeko zilo, appelation de la bouche (Lhande, 944). Hemen ahoa beti zerbaiten galdez, gormanta edo sabelkoi den norbaitez. OEH: sudurpeko: bigote. Sudurpeko beltz, luze, erpin-zorrotza (Azkue). Sudur-peko xiloa ('ahoa') OEHn ez dago. Sarean ez dago.

F: 'être porté sur la bouche' (vieilli): 'être très gourmand' (A.Rey, 100). 'Avec gueule', synonyme de 'bouche', 'être fine gueule': 'être gourmet'. 'Manger, boire à ventre déboutonné' (vieilli) (ibid., 905).

135. Sudur pintzak bereak ukan: [apez batez] irakurle maitea jakin zazu sudur pintzak bereak zituela euskaraz ala erdaraz hasten zelarik doi bat gataskan (13, 108, 7). Azalpena: pintz, phlyctène, cloche, ampoule. Par analogie, sudur pintzak: ailes du nez. Synonyme: sudur-mizpirak. Sudur pintzak hanturik: le nez gonflé de colère. Sudur pintzak bereak ditu, c'est un homme irascible, arrogant, insolent (Lhande). OEH : sudur pintzak, ventanas de la nariz. Sudur pintzak hanturik, les narines enflées de désir, de colère, etc. Sudur-pintzak bereak, sudur-xixtuak adiarazten dituenak, koleratsua (Gure Almanaka, 1954, 53). Sarean Etxeberriren bi adibide badaude, bat gainekoa delarik.

F: 'se mettre en colère'.

136. Sudur pintzak kitzikatu: [Irisartar borrokalariak]: onez-onean bautuzko gizonak bainan gutien ustean, sudur pintzak kitzikatu gabe odola irakitzen (13, 113, 13). Adiera: kitzika, 1) excitation. 2) tracasserie, provocation. 3) critique. 4) adj: excitant, importun (Lhande, 603). Sinonimoa: zirikatu. OEH : 1) agacer, exciter soit matériellement, soit au fig. par paroles ou autrement. Au fig. exciter, provoquer, tracasser, harceler. Zakburra kitzikatzen duenak, asikia nabi (Harriet). Sareak ematen du JB Etxeberriren gaineko adibidea.

F: 'chercher querelle à quelqu'un', 'chercher dispute à quelqu'un en étant agressif' (Rey, 782). 'Chercher des poux à qqn', 'lui chercher querelle pour des mauvaises raisons' (ibid., 760).

139. Ttirit eta taneko: Misionest horiek bederatzi predeiku, dituzten guziak, eta gero ttirit eta taneko" (9, 72, 30). Adiera: ttirit, bagatelle, futilité (Lhande, 965). Taneko, petto-ren sinonimoa (?). Lhande : tanka II: manque, perte d'un coup à la pelote, petto. Ttirit: refus méprisant (Azkue). OEH : Ttirit eta taneko ez daude. Sarean ez da atxematen. Ttanka, un poquitín, Ttanka falta dik, le falta un poquitín (BN, Mixe).

F: 'rien du tout', 'rien de rien' (Rey, 803), double zéro. 
140. Tomate iduri piperra: [Athor apeza]: Attor, ez fida horren itxurari! Tomate iduri biperra! dena den lagun guzietan goxoena! Dena bake: eta bihotz on! horra zertazkoa den bere jukutria guzia (13, 108, 1). Azalpena: 'gizon iduriz haserrekor, bainan funtsean eztia', ,homme coléreux mais ayant bon cour'.

F: 'un coléreux au cœur tendre' (ne se trouve pas dans le dictionnaire des locutions françaises d'A.Rey). Par contre, 'avoir un cour d'artichaut' pour A.Rey, c'est avoir un cœur inconstant et cela se dit d'un amoureux volage (ibid., 35).

141. Tripa, zazpi tripa jabe izan: [de Foucauld]), ba, beti bezala sekulan bezein alferra ta gormanta Xarles hezgaitza... Berriz diot, kasik erran ditake zazpi triparen jabe dela $(13,87,11)$. Azalpena: 'gormant, sabelkoi'. OEH: tripa (ventre, intestins) est employé uniquement pour parler de gros mangeurs (?), de festoyeurs? Gizonentzat ahalge tripa handiegi (Hiribarren, Eskaraz eguia, 15) Sarean ez dago.

F: hitzez hitz: avoir sept ventres. 'Être goinfre, glouton'. 'Manger comme un ogre', 'avoir un appétit d'ogre', manger beaucoup ou goûlument (Rey, 653). 'S'en mettre jusqu'au trou de nez, s'en mettre plein les trous de nez', manger gloutonnement (ibid., 890).

142. Xifritua, (nigarrez xifritua) izan: [1914. urtean egilearen gerlara joan beharra], nik bameka urte, familiako bamabirugarrena...Denak tristezian bondatuak. Bibaramunean ene anaiak gerlarat joan beharra. Hantxet ene ama maitea, begitartea nigar turrustez xifritua (13, 43, 17). Hemen, 'être en larmes, abîmée d'inquiétude'. Azalpena: 'urduri', 'arranguratua', hemen nigar egiteraino. Lhande : xifritua: impatient à l'extrême, être sur le gril, xifritzen ari nintzen zure begira. OEH : Xifritu, Lhanderen definizioa berriz hartua da. Ez du bada biziki laket beha egoitea. .. Aise xifritzen (Herria, 23-10-1958). Sarean ez da.

F: 'être (mettre) sur le gril', dans une situation pénible ou embarrassante. Métaphore qui renvoie au martyre de Saint-Laurent qui mourut brûlé vif sur un gril. De même dans l'expression 'être sur des charbons ardents' (Rey, 480).

143. Xintximarriak ikusi, pairatu: [Hitlerek] bertzelako xintximarriak ikusiko ditu ondoko egunetan aintzidari obore gose, handikariak (13, 15, 4). Azalpena: Xintximariak, sangsues, xintximarriak ikusi: anitz pairatu. Souffrir le diable (Lhande, 1042), souffrir les pires tourments (P. Xarriton, 246). OEH : Xintximari, 1) sangsue, corruption de xintxibare que porte Pouvreau et qui est inusité aujourd'bui. Ardo zaharra eta baba zaharra, xaharren erremedioa. Zintzimarria berriz gazteena (Aspiroz, "Euskal hiztegiaren gehigarriak Nafarroan », Euskara, 1982). 2) tribulations: txintximariak ikusi edo pairatu. Pasar la pena negra. En voir de toutes les couleurs. Ustez ura den edo zerbait edari goxo trago bat iresten da, eta han dira orduan xintximariak! Giranoia guneka errez (Etxepare, Mediku solas). 3) txintximariak baditu: il ne tient pas en place. Sarean ez da.

F: 'en voir de toutes les couleurs', avoir des expériences de toutes sortes, en général des épreuves, des difficultés (Rey, 253). 'Être (mettre) sur le gril', cf. supra. 
144. Xita-miruka eraman, iragan: - [Saint-Pierre]: boriek guziak bola, balio ote $d u$ erraitea bere etsaminak gainez-gain eta xita-miruka iragan dituela? $(9,71,27)$. - Louis Edouard Cestac: han ere ezin gehiago langile ona agertu zen lehen prima, sari guziak airez-aire eremaiten zituela chita-miruka (3, 119, 30). Adiera: 'errex, laster, brauki', miruak xita harrapatzen duen bezala. Lhande : Xita miruka: sans coup férir, comme en se jouant. OEH : Xita-miruka, txita-miruka, Lhande definizioa errepikatuz. Hamar kintzeak Lekondarrek deramatzate xita-miruka (Etxepare, Buruxkak, 27). Sarean, klasikoetan atxematen da Etxepare medikuaren adibide bera eta euskal lokuzioak sarean, bi adibide, biak JB Etxeberrirenak.

F: seulement approché, 'sans coup férir', 'sans difficulté', 'sans avoir à lutter'. Actuellement veut dire 'à coup sûr '(Rey, 257). 'En un éclair', en un instant très bref (ibid., 342).

145. Xitun izan: [Afrikako beltzen sal-erospenak XVIII mendean] Galeriano boriek kinka gaixtoenetan egon behar ixil eta xitun..." (13, 72, 18). Hemen, "les galériens devaient rester silencieux et soumis'. Azalpena: Xitun: penaud, capot, confit (Lhande, 1046) eta OEH, XVI, 151). Ellande ohera badoa, ixil eta xitun, Mariaren makbila, bizkar hezurrean gainera eror dakbion beldurrez (Barbier, Supazter Chokoan)) ; con reduplicacción intensiva: Bainan Jon Doni Petrik ihardetsi zion, xitun xitun", (Barbier, Légendes du Pays Basque, 63). Euskal lokuzioak sarean guneak ematen ditu Etxeberriren bi adibide, bata gainekoa hura bera delarik.

F: 'être capot, être surpris, ruiné, vaincu': expression vieillie (milieu XVII ${ }^{\mathrm{e}} \mathrm{s}$.), (Rey, 138).

146. Xitxi-paperetan artatu: [Santa Elisabeth Hongriako Erreginak andere esposeri aholkuak] Zure senarrak bihotz ona badu ere, orboit estomaka araberakoa duela eta beraz ongi arta zazu zure jauna xitxi paperetan $(13,45,16)$. Paperak: 'papiers', bainan hemen jateko haragi gauzetan, jateko gauza hoberenetan. Azalpena: 'Xitxi gaietan', gauzetan. Lhande : Txitxi: viande, chair. Txitxipapa: 'bamboche'. Txitxipapetan ari dira aspaldian, Lapurdi, Ainhoa, depuis longtemps ils vont de bamboche en bamboche. OEH : carne, en su origen, vOz propia del lenguage infantil. Alde aldean jartzen zaio bethiko arrotza, berehala galdeka: xitxi ta papa, papa buxtia (Barbier, Legendes du Pays Basque, 24). Xitxi-paperetan ibili, ogi-bustiarekin zerbait ona haurrak jastatzen duelarik (P. Xarriton), arno azukratian ogi-puska bustitzea (H. Duhau). Sarean ez da atxematen.

F: hitzez hitz 'soigner qqn dans les choses du ventre, de la panse, le bien nourrir' ; ez dut frantsesezko kidekorik atzeman.

147. Xortekoa, ene xortekoa izan: Dominique Larrart. Ene xortekoa zen, lehengoek zioten bezala. Klasa hogoi-ta-birua; orai denak badazkizu" $(9,59,3)$. Adiera: xorte, tirage au sort, xortekoa izan, être de la même classe d'âge (Lhande, 1051). OEH : Xorte, zorte (, XVI, 920-921): 1) chance, destinée, hasard. 2) clase, especie, tipo. 3) part correspondante. Rezebi dezatenzát bekhatuen barkhamendua, eta zorthea sanktifikatuén artean (Leiçarraga, Act., 26, 18). Sinonimoak : parte, ondare). 4) tirage au sort pour le service militaire : xortean, osasun bazkarrekoa ez 
izanez, ez zuten on-hart ( Laffitte, Euskal literaturaz, 254). Hemen, adin berekoa izan, 'être de la même classe d'âge ou de recrutement'.

F: 'être de la même classe' (en parlant de qq'un, avoir été conscrit ensemble, dans la même année d'appel). Vient du temps où l'appel au service militaire se faisait par tirage au sort. (Rey, 202).

148. Zazpi etchetako herrian galtzea: irakurtzalea obartua diteke gure saindugaia eztela zazpi etchetako herrian galduko den gizon enuchent beietarik. Azalpena: 'inuxenta, tetele izan'. Lit: 'se perdre dans un village comptant sept maisons', 'être bêta, simplet, innocent'.

F: 'être bête comme un âne, une oie, une cruche, un panier, comme ses pieds'. Ces locutions expriment la stupidité (Rey, 75) mais sont plus péjoratives que l'expression basque ci-dessus. 'Ne pas trouver l'eau dans la mer, au lac, à la rivière', être incapable de trouver les choses les plus abondantes, les plus faciles à découvrir (ibid., 338).

149. Zehe bat sudurrekin gelditu. Bi zehe bete sudur: Nor uste duzu abalgetu zela? Nor? Nor! Nor gelditu zehe bat sudurrekin? Nor" (9, 26, 13). Eta erresumako buruzagiak, amor emanik, zehe bat sudurrekin gelditu! (3, 45, 12).Azalpena: 'harriturik gelditu'. Zehe: 1) menu, petit. 2) empan, mesure du bout du pouce au bout du petit doigt, la main étendue. Zehetasun, minutie, simplicité. (Lhande, 1078). Xehe: menu, de peu d'importance (Lhande, 1035). OEH : 1) zehe, xehe, petit, minutieux. 2) empan du pouce.

Bi zehe sudur: un palmo de narices, un pied de nez : Mattin bi zehe sudurrekin ba omen zagon heieri so (Laffitte, Murtuts eta bertze, 23). Eta haren irabazia izanen da bi zehe bete sudur erran komuna den bezala (Tartas, Ontsa biltzeko bidea). Zehe bat sudur egin, Azkue? EY (lokuzioak sarean).

F: 'rester comme deux ronds de flan' (Rey, 421). Rester en plan, le derrière par terre, rester coi.

150. Zerika izan: - Nibork ezin erran zerika ditazken ilunbetako labaki boriek," $(13,72,6)$, hemen: zertarako balio zuten labaki horiek. - - Hastapeneko moldetarik ezagun baitzuen zerika aterako zen geroari buruz (13, 85, 16). Azalpena: zer, zertaz (izan). Lhande : Equivalent de l'interrogatif latin Qualis: quel, quelle, de quelle sorte, de quelle espèce, de quelle nature? Au sujet de quoi. OHE : zerika, zerikako: quel, de quelle nature, caractère ou qualité. Zerika da gizon hori?, de quelle nature est cet homme? (Duvoisin). Zerika zaizu haur hartaz, à quoi jugezvous cet enfant propre? Pouvreau, Dictionnaire. Sarean ez dago.

F: 'Quelle est la nature de, de quelle nature est, comme quoi est ceci ou cela' ....

152. Zimur-zimurra bozkariotu: - Zer pasatuko da bura baitan? zainak lazdura batek hartuko? edo oraino zimur-zimurra bozkariotuko gogoari emanez lanjer guzietarik kanpo dela $(13,88,31)$. Azalpena: Bozkarioak aurpegian zimurrak 
agerarazi, avoir le visage "plissé" de bonheur. Lhande : bekobkia ximur, le visage froncé. OEH : herrestan ote haiz beti beilaz beila joakil ezpain ximurrak irri, barnea urrik ( Iratzeder 188). Jautsi ginen eta bide sabetsean jarrri, sudurra zimur, barri meta batzuen gainean. (Saint-Pierre, Ikusiak, Egan, 20). Sareak ez du ematen.

F: manifester sa jubilation, avoir le visage plissé de jubilation. Ez dut atzematen frantses baliokiderik.

153. Zinak eta minak pairatu: [Charles de Foucauldek] laster pairatu zituen -eta nolako kuraie kalipuarekin- zinak eta minak. Ikusi oraino ez izarrak eguerditan bainan, euskaldun zirtolariek dioten bezala, ikusi akilimarro, galtxagorriren zazpi adar makatzaile, uspelkorrak. (13, 89, 26). - Elizatik ateratzean emazteak kalapita gorrian. Hango zinak eta minak (9,18,29). Azalpena: 'pairamena, sumindura, larritasuna'. Lhande : Expression usuelle exprimant la souffrance. Sinonimoa: zinez eta minez. OEH: zinak eta minak, 1) Angoisses, han izanen dira zinak eta minak, c'est là (en enfer) que seront les souffrances vraiment dites, (Harriet). Zinak eta minak ikusi, sufrir muchissimo (Azkue, EY III, 399). 2) Imprecación: aditu zuen arrangura zirela haren adinaz hango parropiantak. Ondoko igandean pedeiku alkbitik han ziren zinak eta minak, erasi eta oibu patarrak! (Herria, 10-2-1959). "Euskal lokuzioak sarean" guneak ematen ditu Etxeberriren lau adibide eta Azkueren beste bat.

F: 'souffrir le diable, en voir des vertes et des pas mûres'.

154. Zipote, zipote abantailosa: [Arseko apezak lagun lodi bati] irriak eta trufak barna sartu zaizkon gure zipote abantailosari (13, 80, 25). Azalpena: 'tripaundi, sabel-handi', ventru, obèse (Lhande, 1093). OEH : 1) Atropello. 2) Trompo. 3) Huraño. 4) Ventru, obèse: lehen aztaparrak bipil bezain orai larru gizen zipote barnean kokatuak (Salaberry, Gure Herria, 9 -7- 1959). Klasikoak gordailuan gunean agertzen da hitz hurbil bat: zipoteka (bousculant, sautant).

F: 'gros lard, gros plein de soupe', termes d'injure (Rey, 537).

155. Ziria eman: Betidanikoa zuen lañotasun hori; bakotxari zur beretik ziria emanez bainan beti ele ona, buruak eta bibotzak manatzen zioten bezala $(9,15,4)$. Azalpena: 'ziria sartu, trufatu': jouer un tour (litt. enfoncer une cheville) (Lhande). OEH: ziria eman, engañar. Irakurtzen ez ikasiagatik, buruan argia bazuen, eta nori nai ziri ederrak sartzen bazekien ( Mujika, Pernando Amezketarra 19). Idem. Ziria sartu, ziria sakatu.

Bañan zubek ere ezer ez bezela ta burubari atzegiñaz erdizka esan ta osorik adiazitzeko gisan sartzen dituzute ziri onak (Soroa M, Baratzan, 1886, lokuzioak sarean)

F: jeter une pique?

157. Zorro-zipote: bertze batzuen zorro-zipote nasaiak urrezko muntraxena ospetsuez hein bat lorioski trebeskatuak" (9, 8, 6). Azalpena: zorro, 'zaku', fig. 'sabel'. 
Zipote, ventru-obèse. Ikus esamoldea: ateratu zakutik edo zorrotik: je le lui tirerai du sac ou de la poche (Lhande). OEH: 1) zorro, zaku. Zakutik bibia gal edo zorroti irina, da galtze berdina. 2) ventre des animaux, fam. bedaine. Aratxeak, sortzean, pantza edo zorroa bezein handi du gatzagia (Herria, 23-6-1960: gatzagia: 'caillette'). 3) vientre de una mujer: primaderan egin lana/ udazkenean agertu/ ene maiteñoari zorroa loditu (Mendia bete elurrez, Xaramela). Ikusi dituztan adibideetan, zorro biribila, zorro-handi aurkitzen da, aldiz ez zorro-zipote.

F: 'gros lard, gros plein de soupe'.

158. Zotza bezein alferra izan: [Foucauld] hartze onekoa segur bainan zotza bezein alferra, $(13,85,18)$.

Azalpena: arrunt alferra. Lhande : Zotza: 1) bâtonnet 2) lan zotzik ez du egin: il n'a pas fait le moindre travail (xotx: diminutif de zotz). OEH : alfer zotz: kasik Uronttoan bizi ohi zen emazteki bat alferra... bainan alferra! Zotza, hots! Deus fitsik ez omen zuen egiten sekulan (Barbier, Légendes du Pays Basque, 140). Klasikoak gordailuan adibide bera badago beste anitzen artean: (mutil) zotza baino haurra bobe", sortzez Iholdi Urrutiko Isabelle Mendiharat Elissaldek eman erran zaharra.

F: 'paressseux comme une couleuvre, un lézard, un loir, une loche' (Rey, 678).

159. Zunda, zunda handikoa izan: Bego beti nausi, zunda baundiko kondatzailea, ekai gutiz muntatuko baitu saltsa guzia (9, 32, 9). Azalpena: zunda, sonde à sonder les profondeurs. Zunda handia du: il a une grande sagacité (Lhande, 1110). OEHk errepikatzen du Lhanderen azalpena, pénétration d'esprit, sagacité". Ez dago beste adibiderik. Adiera horrekin ez da sarean adibiderik.

F: homme de poids, de valeur, ikus hazta handiko gizona izan eta ospea, gizonaren itzala (G. Garatek, 1095).

Oharra: Paragrafoen zenbakiak ene laneko zerrendakoak dira: adibidez, 109 azpimarratua dena, 109 garren adibidea da (orotora 159 badira) ene zerrendan.

\section{Ondorioa}

Etxeberriren lau liburutako 159 esamolde (eta 50 atsotitz) bildu ditut. Konparatu ditut OEHk eta euskal korpusek ekartzen dituzten esaerekin, eta frantsesezko lokuzioekin, batez ere bere hiztegian Reyek ematen dituenekin. Ohartzekoa da nola Etxeberriren denboran, erran nahi baita XX. mende erditsuan, erran-moldez, zirtoz, ditxoz, erran zaharrez, euskal mintzaira egun baino aberatsagoa zen. Nolaz ez, jakinez bazela alderantzizko diglosia: euskara erabilia zen gehienik eta frantsesa bigarren mintzaira zen, bereziki laborarien munduan.

Azkenean zerrendatu ditut lokuzioak, bi aurkibide eginez, batak euskal lokuzioak eta kide frantesak ematen baititu eta besteak lokuzio frantsesak beren euskal kideekin. Espero dut norbaitek baliatuko duela bere euskara aberasteko. 
Eskerrak beroenak zor dizkiet Koldo Garairi fraseologiako ateak ideki dizkidalako; Henri Duhauri, xehetasun ezin hobeak eman baitizkit; Arberuko erteko moldeez, Dominique Duhalde eta Jeanne Carrère bere emazteari beren lekukotasunengati; P. Xarritoni pundu koropilatuenak argitu baititu, eta nola ez X. Videgaini lexikologiaren gustua eman baitit eta ene lana bultzatu.

\section{Bibliografia}

\section{A) LAN TEORIKOAK}

- 1. Durrieux (C.), : " Le figement lexical. Approche cognitive de l'appréhension du sens", Le figement lexical. Rencontres linguistiques Méditerranéennes, Tunis, Editons Ceres, 1998, 388 orr.

- 2. Fiala ( P.) : "Figements et phraséologie", Courants sociolinguistiques. Séminaire de lexicologie politique de l'Université de Paris II (1986-1987, Paris, Klincksieck, 1989.

- 3. Garai (K), :"Fraseologia, sarrera", (Cowie.A.P, introduction 1-20) Masterra, 2005ko udaberria, Paueko eta Aturriko Unibersitatea, Baionako Kanpusa.

- 4. Gross $(\mathrm{G})$ : Les expressions figées en français. collection Français: l'Essentiel, Paris, Ophrys, 1996.

- 5. Haensch (G), Wolff (L), Ettinger (S), Werner (R): La lexikografia, Madrid, Editorial Gredos, 1982.

- 6. Lakoff (G), Johnson (M): Metaphors we live by. The University of Chicago Press, 1980 [Les métaphores dans la vie quotidienne. Paris, Editions de Minuit, 1985].

- 7. Markuleta (G) : "Udako narrazioa.berba ketan", Berria egunkaria. 2005-08-21.

- 8. Mejri (S.) : Le figement lexical, descriptions linguistiques et structurations sémantiques. Tunis, Publications de la Faculté des Lettres de la Manouba, 1997.

- 9. Valli (A.), Villagenes Serra (E.) : "Locutions figées comprenant une partie du corps en espagnol et en français", Le figement lexical. Rencontres linguistiques Méditerranéennes, Tunis, Editions Ceres, 1998, 388 p, p 177-206.

B) HIZTEGIAK ETA ANTOLOGIAK.

- 1. Bidegain (E) : Euskal esaerak. Donostia, Elkarlanean, 2001.

- 2. Cellard (J), Rey (A) : Dictionnaire du français non conventionnel. Paris, Hachette, 1980-1991.

- 3. Dubois (J) et coll : Dictionnaire de Linguistique et Sciences du langage. Paris, Le Seuil, 1994.

- 4. Ducrot (O), Schaeffer (J.M): Nouveau dictionnaire encyclopédique des sciences du langage. Paris, Le Seuil, 1972-1995.

- 5. Duneton (Cl) : Le bouquet des expressions figurées. Paris, Le Seuil, 1990. 
- 6. Duneton (Cl) : La puce à l'oreille, anthologie des expressions populaires avec leur origine, Le livre de poche, Balland, 1985-1990, 510 p.

- 7. Garate (G.) : Atsotitzak, refranes, proverbes, proverbia. Fundación Bilbao Kutxa, Bilbao, 2003.

- 8. Guillemard (C) : La fin des haricots et autres mystères des expressions françaises, Bastillat, Paris, 2002, 280 p.

- 9. Guillemard (C) : L'affaire est dans le sac. Nouveaux mystères des expressions françaises, Bartillat, Paris, 2003, 250 p.

- 10. Izaguire (K) : Euskal lokuzioak, Eusko Ikaskuntza, 1983.

- 11. Lhande (P) : Dictionnaire français-basque. Paris, éditions Beauchesne, 1926.

- 12. Mantxut lokuzioak, Urmeneta, Komunikazio biziagoa, Lasarte, 200-2002.

- 13. Oihenart: Atsotitzak eta poemak, Baigorri, Izpegi ed., 1992.

- 14. Orotariko Euskal Hiztegia, Euskaltzaindia, Bilbao, Desclèe de Brouwer, 2005.

- 15. Rat (M) : Dictionnaire des expressions et locutions traditionnelles, Larousse, Paris, 1957-1999.

- 16. Rey (A.) : Chantereau (S), Dictionnaire d'expressions et locutions. Le Robert, 1989, 1999, Paris.

- 17. Rey (A) et coll. : Le Nouveau Petit Robert Grand Format, dictionnaire alphabétique et analogique de la langue française, Ed. Le Robert, Paris, 2006.

— 19. Sinonimoen kutxa, Sinonimoen eta Antonimoen biztegia, Elhuyar, 1999-2004.

- 20. Durand $(G)$ : Les structures anthropologiques de l'imaginaire. Paris, Dunod, 1992.

C) SAREAN:

— 1. Euskarazko esaerak, http://www.erabili.com

- 2. Euskal lokuzioak sarean, http://intza.armiarma.com. (Josean Elosegi, Koldo Izagirre, Josu Landak paratuak)

—3. Klasikoen gordailua, http://www.armiarma.com

- 4. Garate (G), atsotitzak, http://www.erabili.com

- 5. XX. mendeko euskararen korpusa (Euskaltzaindiko korpusa), http://www.euskaracorpusa.net

- 6. Trésor de la Langue Française Informatisé sur le net, TLF i, http://www.atilf.atilf.fr 